Cláudia M. L. Assunção

\title{
Análise filogenética em Macrocephala (Tardigrada, Archaeotardigrada).
}


Cláudia M. L. Assunção

\section{Análise filogenética em Macrocephala (Tardigrada, Archaeotardigrada).}

Tese apresentada ao Instituto de Biociências da Universidade de São Paulo, para a obtenção de Título de Doutor em Ciências, na Área de Zoologia.

Orientador: Prof. Dr. Carlos Eduardo Falavigna da Rocha

São Paulo

2001 


\section{Assunção, Cláudia M. L.}

Análise filogenética em Macrocephala (Tardigrada, Archaeotardigrada) 80 páginas

Tese (Doutorado) - Instituto de Biociências da Universidade de São Paulo. Departamento de Zoologia.

1. Sistemática filogenética 2. Tardigrada 3. Macrocephala I. Universidade de São Paulo. Instituto de Biociências. Departamento de Zoologia.

\section{Comissão Julgadora:}


A todos os meus familiares queridos, especialmente meus pais, meus filhos maravilhosos Vinícius, Úrsula, Jordan, e Igor (in memoriam), minha linda sobrinha Manuela e meus irmãos Bete e Zé Eduardo. 


\section{Agradecimentos}

À Fapesp (Fundação de Amparo à Pesquisa do Estado de São Paulo) pelo apoio financeiro que viabilizou a execução do projeto;

Ao Departamento de Zoologia do IBUSP, pelas facilidades e instalações físicas cedidas, assim como aos funcionários, técnicos e colegas pela solicitude e amizade;

Ao Prof. Dr. Carlos Eduardo Falavigna da Rocha, pela orientação científica e acadêmica;

À Coordenação da Pós-Graduação do IBUSP, e aos funcionários de sua secretaria pelos serviços prestados;

À Smithsonian Institution, Washington/D.C., na pessoa de Chad Walter, pelo empréstimo de material biológico;

À Prof ${ }^{\mathrm{a}}$. Dr ${ }^{\mathrm{a}}$. Thais N. Corbisier, do IOUSP; Prof ${ }^{\mathrm{a}}$. Dr ${ }^{\mathrm{a}}$. Liliana Forneris, do IBUSP; Prof $^{\mathrm{a}}$. Dr ${ }^{\mathrm{a}}$. Liliana Medeiros, da Universidade Metodista de São Paulo; e ao Prof. Dr. Pedro M. Arbizu, da Universidade Federal do Paraná, por cederem material biológico coletado em suas pesquisas;

Ao Prof. Dr. Fábio Lang da Silveira, do IBUSP, que gentilmente coletou material biológico na ilha de Itamaracá/PE;

Ao Prof. Dr. Martin L. Christoffersen, da Universidade Federal da Paraíba, pela coautoria no artigo de filogenia de Tardigrada, no manuscrito de filogenia de Stygarctidae, e pela iluminação nas hipotetizações sobre filogenia de Digitopoda, assim como pela amizade sempre dispensada;

A Guilherme R. Lotufo, pela revisão do Abstract; 
A Rodrigo Leão de Moura e Ronaldo B. Francini Filho, pela amizade sincera e pela hospedagem na Vila Madalena, São Paulo, no início do curso;

Ao Paulo G. Harkot, Claudia Kohler e seus lindos e queridos filhos, Marina e Fabio, pela forte amizade, convivência frutífera e hospedagem em Perdizes, São Paulo, no início e também ao final do curso;

A José Eduardo L. Assunção, que “salvou a pátria” com o empréstimo do seu possante notebook, e pela hospedagem Vip no Parthenon Flats, Itaim Bibi, São Paulo, ao final do curso;

À D. Deuza, tia Gracinha, e Agnes, que tornaram possível a minha vinda para São Paulo, ao ajudarem no cuidado com os gêmeos Úrsula e Jordan;

Aos meus pais, que mais uma vez cuidaram do meu compreensivo e querido filho Vinícius;

Ao companheiro e amigo Bernardo, que superou todas as dificuldades e se superou ao desempenhar o papel de pai e mãe dos gêmeos, pelo apoio e eterna cumplicidade. 


\section{Índice}

1. Introdução $\quad 01$

1.1. Stygarctidae 07

1.2. Digitopoda 10

1.2.1. Comentários sobre as relações filogenéticas em Orzeliscinae Schulz, 1963

2. Objetivos 18

3. Material e métodos 19

3.1. Material biológico examinado 19

3.2. Metodologia 21

3.3. Seqüências de grupos externos 23

3.4. Caracteres 24

3.5. Abreviação 24

4. Resultados 25

4.1. Lista comentada de caracteres para Stygarctidae 26

4.2. Relações entre os táxons de Stygarctidae 40

4.3. Lista comentada de caracteres para Digitopoda $\quad 46$

4.4. Relações entre os táxons de Digitopoda 54

4.4.1. Relações filogenéticas propostas para Orzeliscinae 61
63

5.1. Stygarctidae 63

5.2. Digitopoda 66

5.2.1. Orzeliscinae 68

6. Conclusões 70

7. Resumo 71

8. Abstract 72

9. Referências bibliográficas 73 


\section{INTRODUÇÃo}

Os Tardigrada constituem um táxon pouco estudado no que diz respeito ao seu status como grupo, quanto à sua posição no sistema dos Metazoa e quanto a um sistema geral para os seus subgrupos.

As monografias de MARCus (1929, 1936) estabeleceram a divisão dos grandes grupos de Tardigrada. Ainda hoje, os grupos taxonômicos de tardígrados estão basicamente distribuídos em duas classes: Heterotardigrada e Eutardigrada. Heterotardigrada, que reúne espécies marinhas e limno-terrestres, é dividido nas ordens Arthrotardigrada e Echinischoidea (MARCUS, 1927). Outros táxons supraespecíficos foram acrescentados ao sistema de Marcus: a classe Mesotardigrada (RAHM, 1937), as ordens Parachela e Apochela (SCHUSTER et al., 1980), e a ordem Thermozodia (RAMAZzoTTI \& MAUCCI, 1983) (Tab. 1).

RAMAZzoTTI \& MAUCCI (1982) produziram uma detalhada história taxonômica de Tardigrada. Seguiu-a a terceira e última edição de uma compilação enciclopédica das 531 espécies de tardígrados conhecidas até então (RAMAZzotTI \& MAUCCI, 1983). A última revisão do grupo foi publicada por KINCHIN (1994), que apesar de reunir informações importantes numa leitura agradável e didática, não atualizou o número de espécies e não esclareceu as relações filogenéticas no grupo. Atualmente, 889 espécies de tardígrados estão descritas, das quais 148 são primariamente marinhas.

Abordagens filogenéticas, que não seguem fielmente o método henniguiano, foram propostas para as famílias de Heterotardigrada (KRISTENSEN \& HigGINS, 1984a) e Eutardigrada (BERTOLANi \& BiSERov, 1996), para os gêneros de Stygarctidae e famílias relacionadas (BELLO \& DE ZIO GRIMALDI, 1998), para as subfamílias (PollOCK, 1995) e gêneros de Halechiniscidae (RenAud-MoRNANT, 1984), para os 
gêneros de Styraconyxinae (KRISTENSEN \& RenAud-MoRnAnt, 1983) e para as espécies de Styraconyx (KRISTENSEN \& Higgins, 1984b) e Florarctinae (RENAUDMORNANT, 1987). KRISTENSEN (1987) elaborou uma análise filogenética manual para os 12 gêneros de Echiniscidae, da qual foram extraídos 35 caracteres, analisados em uma abordagem cladística recente (JøRGENSEN, 2000).

Tabela 1 - Classificação esquemática do filo Tardigrada. Os táxons marcados com * são esclusivamente marinhos; o restante é composto predominantemente de espécies limno-terrestres. Os números entre parênteses indicam a distribuição de 102 gêneros recentes que compõem o filo (modificado de KinCHIN, 1995).

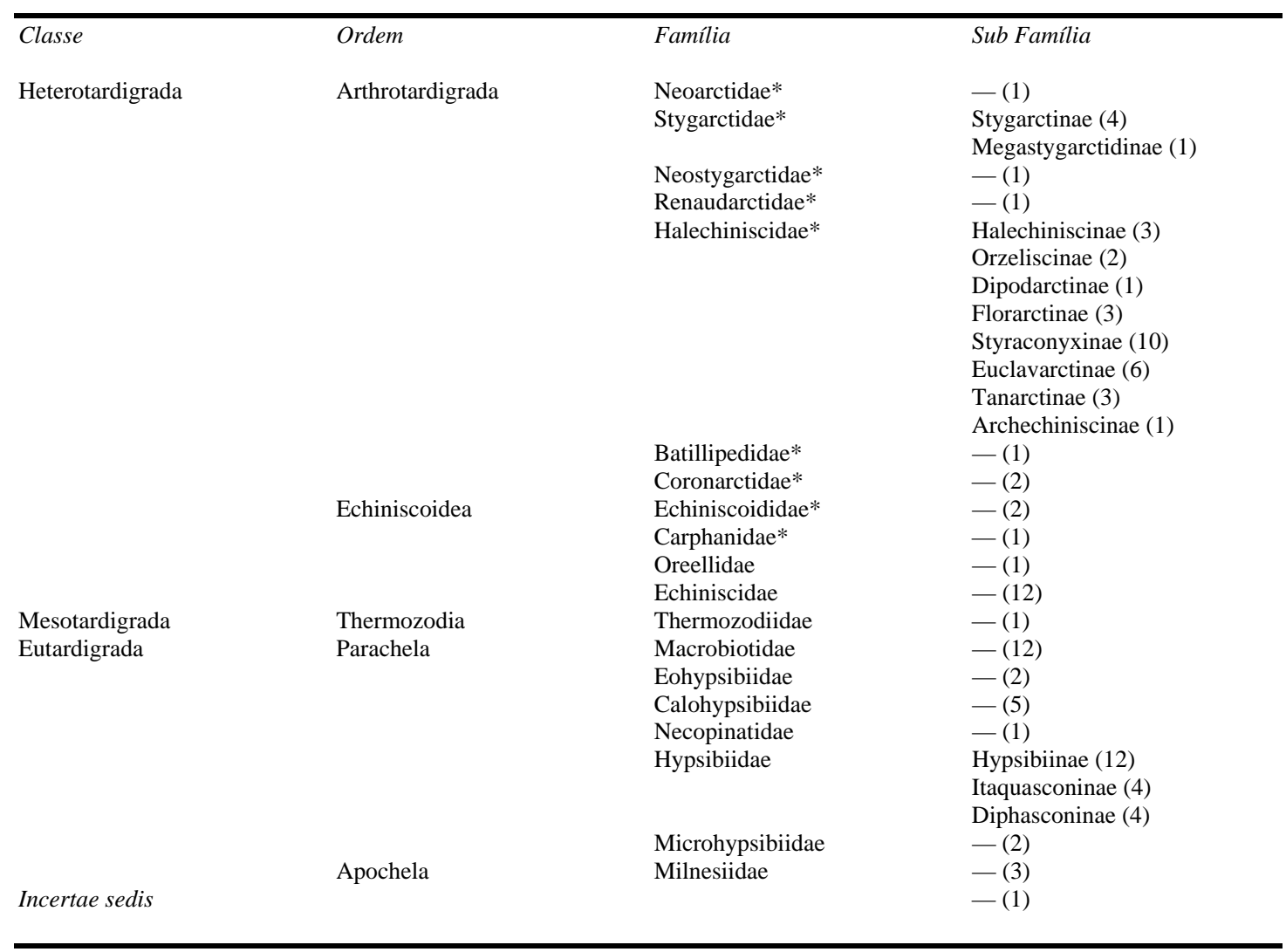

Geralmente reconhecidos como um filo, os Tardigrada são intrigantes animais metaméricos recentemente posicionados no táxon Ecdysozoa por AgUiNALDO et al. (1997), em sua análise molecular. Uma discussão detalhada das relações internas desses ecdisozoários, baseada na morfologia dos grupos, também foi apresentada por Christoffersen et al. (1997). Segundo esses autores, Aschelminthes é considerado 
um grupo monofilético que, junto com Pentastomida e Tardigrada, forma um clado considerado como grupo-irmão de Arthropoda. Esta proposta opõe-se à maioria das hipóteses anteriores, inclusive aquelas originadas por análises moleculares, que aproximam Tardigrada de Onychophora e Arthropoda, formando o tradicional táxon Panarthropoda. Entretanto, o sistema de CHRISTOFFERSEN et al. (1997) esclarece a controvérsia acerca do posicionamento do filo, que compartilha caracteres tanto com Arthropoda (e.g., presença de placas cuticulares e apêndices birremes) quanto com Aschelminthes (e.g., aparato bucofaríngeo e perda de órgãos respiratórios, circulatórios e excretórios).

ASSUNÇÃO \& CHRISTOFFERSEN (1994), numa análise cladística preliminar dos táxons superiores de Tardigrada e, mais recentemente, na versão revista e atualizada dessa análise (CHRISTOFFERSEN \& ASSUNÇÃO, no prelo), propuseram um novo sistema para o grupo (Figs. 1 e 2, Tab. 2). Neste sistema, Heterotardigrada, Arthrotardigrada e Echiniscoidea não foram aceitos como táxons monofiléticos. Em contrapartida, propuseram Digitopoda como um táxon superior cuja sinapomorfia é o surgimento único de dígitos e que inclui a maioria dos tardígrados marinhos (i.e., Neostygarctus, Halechiniscidae, Renaudarctidae e Batillipedidae). Além disso, Digitopoda foi considerado grupo-irmão do táxon marinho Stygarctidae, ambos incluídos em Macrocephala. Neoarctus, desvinculado de Stygarctidae, serve como grupo externo a Macrocephala. A proposição deste último táxon baseia-se, entre outros caracteres, na hipótese de incorporação, à cabeça, de um par de apêndices sensoriais (cirro lateral e clava primária) normalmente localizados na região escapular ou perdidos no restante dos táxons de Tardigrada. Adicionalmente, Prototardigrada foi proposto como grupo-irmão de Macrocephala, que reúne todos os outros táxons de tardígrados. 


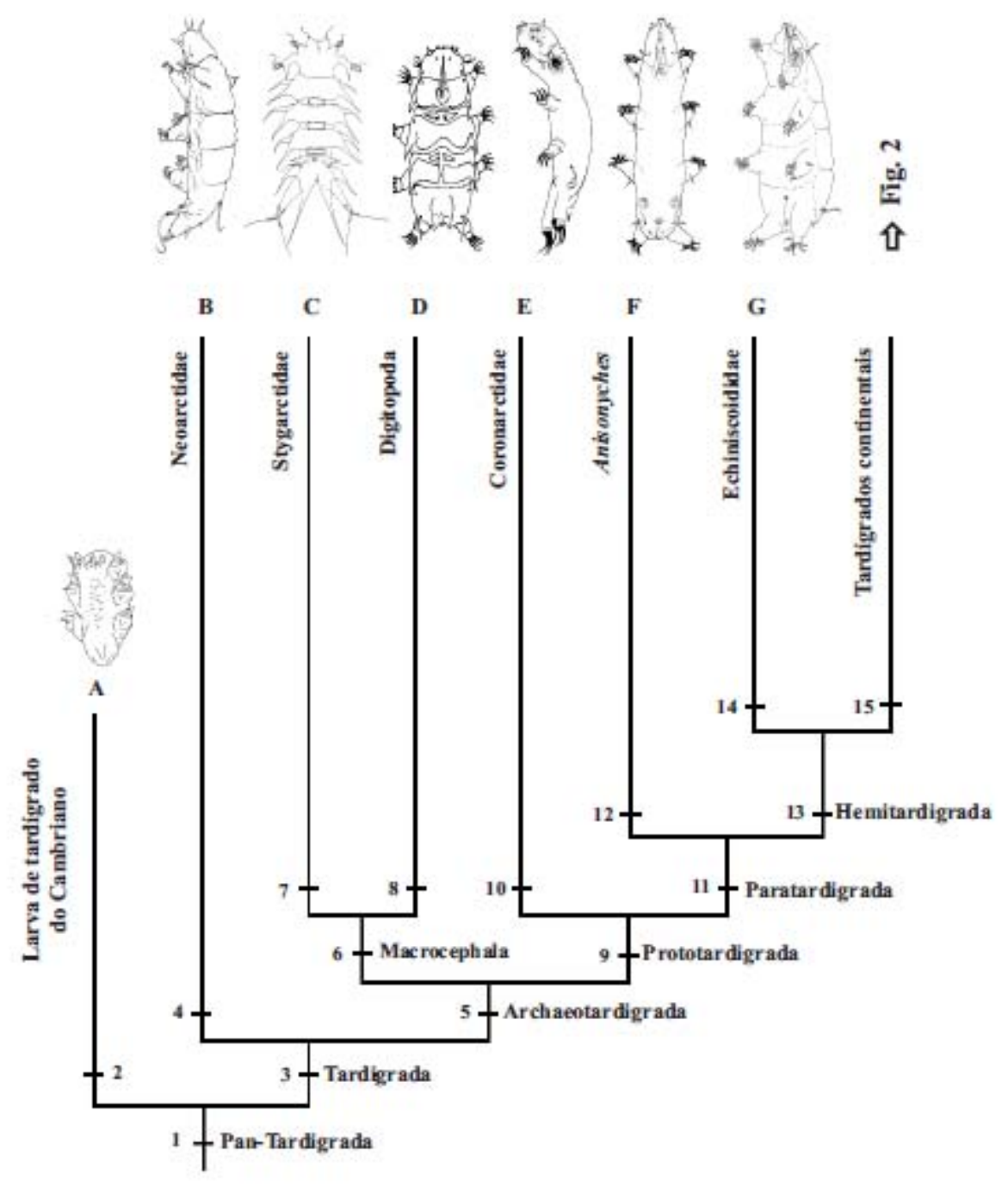

Figura 1- Filogenia proposta para os tardígrados primariamente marinhos (CHRISTOFFERSEN \& AssunÇÃo, no prelo). As figuras foram modificadas a partir das seguintes fontes: A- Larva de tardígrado do Cambriano (MüLleR et al., 1995: 110, fig. 3 a); B- Neoarctus primigenius (DE ZIO GRIMALDI et al., 1992: 311, fig. 1m); C- Parastygarctus biungulatus (DE LUCIA MORONE et al., 1984: 87, fig. 1); D- Renaudarctus psammocryptus (RENAUD-MORNANT, 1988: 362, fig. $33.1 \mathrm{~h}$ ); ETrogloarctus trionyches (VILlORA-MORENO, 1996: 278, fig. 2b); F- Anisonyches mauritianus (DE ZIO GrIMALDI et al., 1988: 355, fig. 5 a); G- Echiniscoides higginsi (HALlAs \& KRISTENSEN, 1982: 189, fig. 1 a). Caracteres apomórficos: 1a. Desenvolvimento epimórfico, larvas com três pares de pernas reduzidas e robustas no tronco; 2a. Larvas com duas garras desenvolvidas em forma de esporão em cada perna, terminando em uma a quatro extremidades pontiagudas; 3a. Larvas e adultos com quatro pares de pernas no tronco; 3b. Cada perna com duas garras alongadas nas larvas, quatro garras alongadas nos adultos; 3c. Presença de cirro E, consistindo de um cirróforo basal e um flagelo articulado longo; 3d. Tagma cefálico no adulto consistindo de três metâmeros com três apêndices pares e um cirro médio único; 3e. Pernas com ramos externos reduzidos a papilas coxais; 3f. Cérebro com dois lobos externos, conectados ao primeiro gânglio torácico por um par de nervos circum-esofágico e dois lobos internos conectados diretamente ao gânglio subesofágico; 3g. Primeiro par de apêndices cefálicos modificado em estiletes bucais perfurantes pares e seus respectivos suportes; 3h. Apêndices do segundo e terceiro metâmeros cefálicos, assim como os apêndices da placa escapular dorsal, consistindo de um cirro mecanoreceptor e de uma clava quimioreceptora (contendo as vesículas de Van der Land); 4a. Pernas 1-4 no adulto com apenas três garras; 4b. Cirro cefálico mediano com cirróforo arredondado; 5a. Lobos externos do cerébro com um par de olhos simples; 5b. Região anterior da cabeça curvada ventralmente, de modo que os cirros cefálicos externos se tornam ventrais, enquanto que os cirros cefálicos internos permanecem no dorso da cabeça; 5c. Clavas terciárias localizadas na região anterior da cabeça; 5d. Pernas com articulações telescópicas; 5e. Espinho terminal da papila coxal na perna 4 reduzido ou ausente; 6a. Placa escapular (com clavas primárias e cirro A) incorporada 
ao tagma cefálico, o qual passa a ter quatro metâmeros; 6b. Perna 4 consideravelmente mais longa que as pernas 1-3 (devido ao alongamento da coxa); 6c. Placas torácicas dorsais com um par de projeções laterais; 6d. Cabeça dividida em seis lobos; 7a. Clavas terciárias ausentes; 7b. Placas torácicas com poros mediano-ventrais; 7c. Olhos ausentes; 7d. Base da clava primária e do cirro A sem cirróforo robusto (apêndices cefálicos não-pedunculados); 8a. Presença de dígitos únicos sustentando cada garra; 9a. Garras com esporão basal; 9b. Apêndices escapulares (clava primária e cirro A) não-pedunculados; 10a. Clavas secundárias formando placas sensoriais (corona) estendidas sobre a superfície dorsal da cabeça; 10b. Perna 4 com garras alongadas; 10c. Olhos ausentes; 11a. Cirro cefálico mediano reduzido ou ausente; 12a. Perna 4 no adulto com apenas três garras; 13a. Existência de adaptações fisiológicas à dessecação em ambientes intertidais; 13b. Corpo com musculatura oblíqua-estriada; 14a. Presença de seis ou mais garras em cada perna do adulto; 14b. Garras sem esporão basal; 15a. Perda do cirro E original com cirróforo; 15b. Habitat primariamente limno-terrestre.

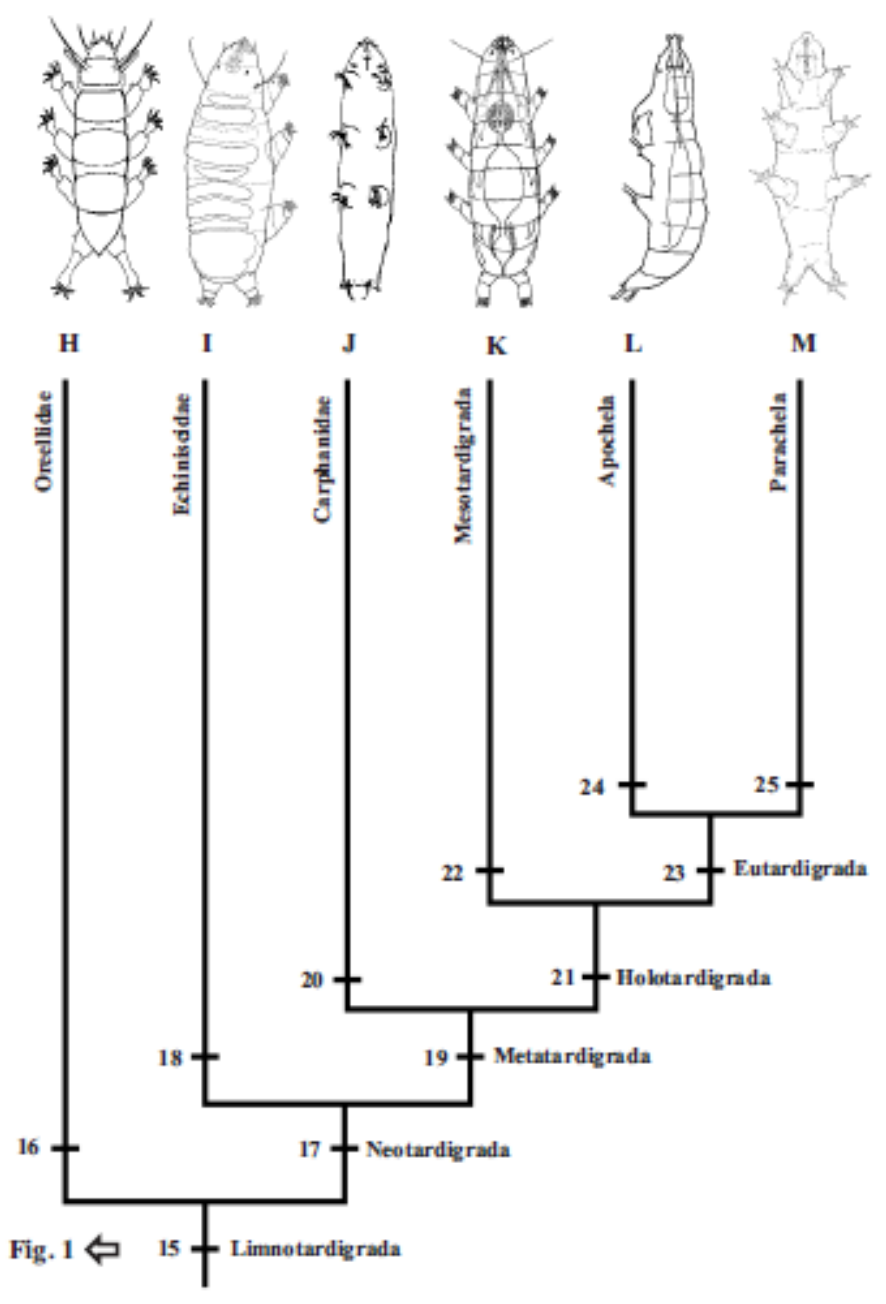

Figura 2- Filogenia proposta para os tardígrados primariamente continentais (CHRISTOFFERSEN \& AsSUNÇÃO, no prelo). As figuras foram modificadas a partir das seguintes fontes: H- Oreella mollis (KRISTENSEN, 1987: 328, fig. 45 a); I- Parechiniscus chitonides (KRISTENSEN, 1987: 298, fig. 36); JCarphania fluviatilis (REnAUD-MoRnAnT, 1988: 364, fig. 33.3 k). K- Thermozodium esakii (RAHM, 1937: 347, fig. 1). L- Milnesium tardigradum (MARCUS, 1936: 322, fig. 302 a). M- Isohypsibius granditintinus (CHANG \& Ho, 1996: 247, fig. 1 a). Caracteres apomórficos: 15a. Perda do cirro E original com cirróforo; 15b. Habitat primariamente limno-terrestre; 16a. Presença de uma projeção caudal mediana curta; 16b. Pernas 2-3 sem papilas coxais; 16c. Olhos ausentes; 17a. Receptáculos seminais pares ausentes (ou, algumas vezes, apenas um único receptáculo seminal presente); 17b. Ovos depositados na exúvia; 17c. Articulação não telescópica entre a coxa e a tíbia; 18a. Presença de placas dorsais robustas; 18b. Pernas 2-3 sem papilas coxais; 18c. Celomócitos ancorados na parede do corpo; 18d. Herbívoros de briófitas; 19a. Cloaca presente; 19b. Clavas primárias e secundárias ausentes; 19c. 
Articulações telescópicas nas pernas reduzidas ou ausentes; 20a. Pernas 4 reduzidas a duas projeções caudais, cada uma com uma garra longa e flexível; 20b. Perna 4 sem papilas coxais; 20c. Pernas 1-3 com apenas duas garras e perna 4 com uma garra no adulto; 20d. Olhos ausentes; 21a. Presença de quatro papilas peribucais; 21b. Cirros cefálicos internos ausentes; 21c. Faringe sem barras cuticulares; 21d. Faringe com micro- e macroplacóides; 21e. "Túbulos de Malpighi" presentes; 22a. Seis a dez garras nas pernas do adulto; 22b. Esporões basais das garras reduzidos a pequenos processos espiniformes; 23a. Lobos externos do cérebro alongados, ultrapassando consideravelmente o limite posterior dos lobos internos; 23b. Cirro A ausente; 23c. Pernas 1-4 sem papilas coxais; 23d. Presença de seis papilas peribucais; 23e. Esporão basal das garras internas desenvolvido, formando o que se chama de "garras duplas"; 23f. Presença de dois ligamentos dorsais suspendendo os testículos na cavidade do corpo; 23g. Átrio bucal fortemente quitinizado em frente aos estiletes; $23 \mathrm{~h}$. Desenvolvimento direto; 24a. Tubo bucal muito largo e com paredes espessadas; 24b. Garras externas de P1-4 proeminentemente alongadas e sem esporão basal; 24c. Placóides ausentes; 24d. Faringe em forma de pêra; 25a. Pernas com duas garras; 25b. Cirros cefálicos externos ausentes; 25c. Ramos primários e secundários das garras assimétricos.

Tabela 2 - Sistema filogenético seqüenciado para os grandes grupos de Tardigrada (CHRISTOFFERSEN \& Assunção, no prelo). Os números de gêneros e espécies estão indicados entre parênteses. Colchetes incluem os táxons redundantes (monotípicos) (CHRISTOFFERSEN, 1989). Caracteres diagnósticos, baseados exclusivamente em apomorfias, estão indicados entre chaves.

Pan-Tardigrada $\{\mathbf{1 a}\}$

Larva de tardígrado do Cambriano $\{2 \mathbf{a}\}$

Tardigrada Spallanzani, 1776 (102 gêneros recentes, 889 espécies recentes, mais um gênero e uma espécie de eutardígrado

fóssil do Cretáceo) $\{3 \mathbf{a}-\mathbf{h}\}$

Neoarctidae De Zio Grimaldi, Gallo D’Addabbo \& De Lucia Morone, 1992 \{4a-b

[Neoarctus De Zio Grimaldi, Gallo D’Addabbo \& De Lucia Morone, 1992]

[N. primigenius De Zio Grimaldi, Gallo D’Addabbo \& De Lucia Morone, 1992]

Archaeotardigrada, nov. (101 gêneros, 888 espécies) \{5a-e

Macrocephala, nov. (37 gêneros, 131 espécies) $\{\mathbf{6 a - d}\}$

Stygarctidae Schulz, 1951 (5 gêneros, 17 espécies) $\{7 \mathbf{7 a - d}\}$

Digitopoda, nov. (32 gêneros, 114 espécies) \{8a\}

Prototardigrada, nov. (64 gêneros, 757 espécies) $\{$ 9a-b $\}$

Coronarctidae Renaud-Mornant, 1974 (2 gêneros, 6 espécies) \{10a-c

Paratardigrada, nov. (62 gêneros, 751 espécies) \{11a

Anisonyches Pollock, 1975 (3 espécies) $\{\mathbf{1 2 a}\}$

Hemitardigrada, nov. (61 gêneros, 748 espécies) \{13a-b

Echiniscoididae Kristensen \& Hallas, 1980 \{14a-b $\}$

[Echiniscoides Plate, 1889 (8 espécies)]

Limnotardigrada, nov. (60 gêneros, 740 espécies) \{15a-b $\}$

Oreellidae Puglia, 1959 [Oreella Murray, 1910] [O. mollis Murray, 1910] \{16a-c\}

Neotardigrada, nov. (59 gêneros, 739 espécies) \{17a-c

Echiniscidae Thulin, 1928 (12 gêneros, 211 espécies) $\{\mathbf{1 8 a}-\mathbf{d}\}$

Metatardigrada, nov. (47 gêneros, 528 espécies) $\{$ 19a-d $\}$

Carphanidae Binda \& Kristensen, 1987 [Carphania Binda, 1979] \{20a-d $\}$

[C. fluviatilis Binda, 1979]

Holotardigrada, nov. (46 gêneros, 527 espécies) \{21a-e

Mesotardigrada Rahm, 1937 [Thermozodia Ramazzotti \& Maucci, 1983] \{22a-b\}

[Thermozodiidae Rahm, 1937] [Thermozodium Rahm, 1937]

[T. esakii Rahm, 1937]

Eutardigrada Richters, 1926 (45 gêneros, 526 espécies, mais † Beorn leggi) \{23a-h

Apochela Schuster, Nelson, Grigarick \& Christenberry, 1980 \{24a-d $\}$

[Milnesiidae Ramazzotti, 1962] (3 gêneros, 6 espécies)

Parachela Schuster, Nelson, Grigarick \& Christenberry, 1980 (42 gêneros, 520 espécies) $\{\mathbf{2 5 a - c}\}$ 
Outra modificação importante introduzida no sistema referido acima é a proposta do táxon Limnotardigrada, que reúne todos os grupos que compartilham o habitat limno-terrestre. Na classificação de MARCus (1927), esses grupos estavam distribuídos em Heterotardigrada e Eutardigrada. CHRISTOFFERSEN \& AsSunÇão (no prelo) consideram a conquista do meio terrestre como tendo ocorrido uma única vez. Desta forma, resgatam a seqüência evolutiva previamente sugerida por MAY (1953), iniciada com os artrotardígrados marinhos, passando pelos equiniscóideos marinhos intertidais e culminando com os equiniscídeos e eutardígrados terrestres.

O presente estudo, baseado no sistema exposto acima, propõe hipóteses filogenéticas para os táxons incluídos em Macrocephala: Stygarctidae e Digitopoda.

\subsection{Stygarctidae}

Stygarctidae foi criada para abrigar o gênero Stygarctus Schulz, 1951, sendo depois acrescida dos gêneros Parastygarctus (RENAUd-DeByser, 1965a), Pseudostygarctus e Megastygarctides (MCKIRDY et al., 1976), Mesostygarctus (Renaud-Mornant, 1979), Neostygarctus (DE Zio Grimaldi et al., 1982), e Neoarctus (DE Zio GRIMALDI et al., 1992).

KRISTENSEN \& HigGINS (1984a) propuseram Renaudarctidae para acomodar o novo gênero Renaudarctus, transferindo também Neostygarctus para esta família. Esses autores se basearam na presença de dígitos suportando garras nas pernas e na existência de placas cuticulares dorsais, caracteres encontrados nesses dois gêneros. Também foi considerada a presença de dois a quatro espinhos acessórios nas garras de cada perna, apesar dessas estruturas diferirem morfologicamente nos dois táxons. 
DE ZIO GRIMALDI et al. (1987), considerando que as garras de Renaudarctus e de Neostygarctus são muito diferentes e que os dígitos de Neostygarctus não seriam dígitos verdadeiros, criaram Neostygarctidae para abrigar este último gênero.

ASSUNÇÃo \& CHRISTOFFERSEN (1994) e CHRISTOFFERSEN \& ASSUNÇÃO (no prelo), removeram também Neoarctus de Stygarctidae. Em recente análise cladística dos gêneros de Stygarctidae e famílias relacionadas, BELLO \& DE ZIo GRIMALDI (1998) confirmaram que Stygarctidae só é válida após a exclusão de Neostygarctus e Neoarctus.

Foi estabelecido, portanto, um consenso quanto ao monofiletismo de Stygarctidae e suas 17 espécies atualmente classificadas em cinco gêneros: Stygarctus, Parastygarctus, Pseudostygarctus, Megastygarctides e Mesostygarctus. No entanto, são ainda controvertidos o arranjo tradicional de Tardigrada, a posição filogenética de Stygarctidae e as relações recentemente estabelecidas entre os gêneros dessa família (Bello \& De Zio Grimaldi, 1998) (Fig. 3, Tab. 3).

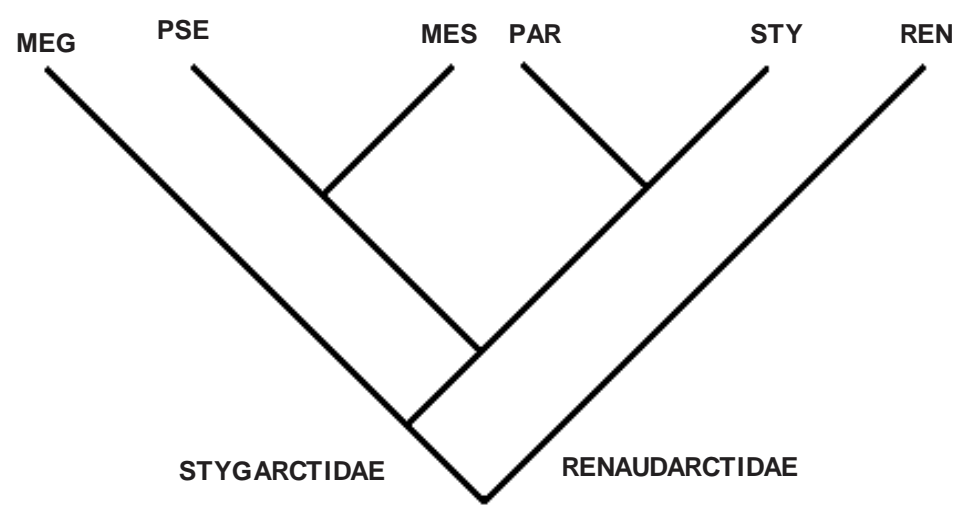

Figura 3 - Cladograma mostrando as relações filogenéticas entre os gêneros de Stygarctidae e Renaudarctidae (modificado de BeLLo \& DE ZIO GRIMALDI, 1998). MEG = Megastygarctides; PSE = Pseudostygarctus; MES = Mesostygarctus; PAR = Parastygarctus; $\mathrm{STY}=$ Stygarctus; REN = Renaudarctus. 


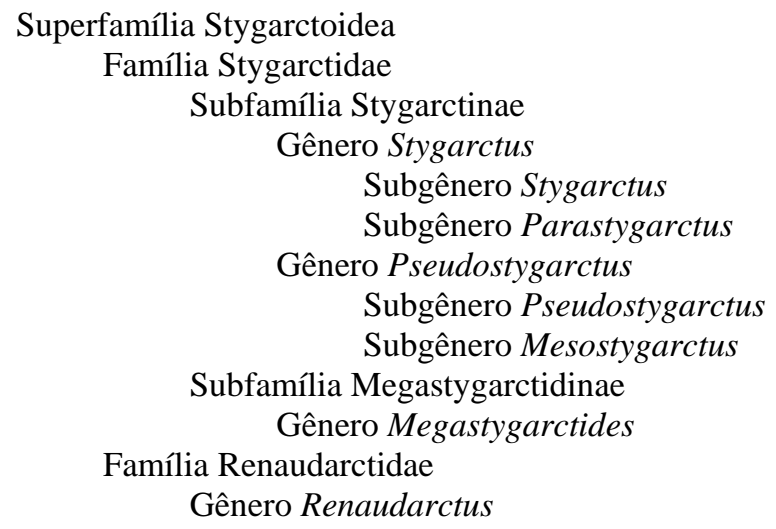

As primeiras hipóteses sobre a posição de Stygarctidae dentro de Heterotardigrada foram propostas por RENAUd-DEByser (1965a,b), RENAUD-MORNANT (1967) e RENAUd-MornAnT \& Anselme-MoizAn (1970). Esses autores sugeriram que as membranas de sustentação das garras nas pernas dos Stygarctidae representariam vestígios de dígitos encontrados na maioria de outros heterotardígrados. Então, os estigarctídeos foram considerados o ramo terminal dos artrotardígrados, e a hipótese de que Stygarctidae representaria um elo de ligação entre Arthrotardigrada e Echiniscoidea foi estabelecida (DE LUCIA Morone et al., 1984). Esta hipótese, no entanto, não é suportada em um contexto filogenético, mesmo quando uma suposta relação de grupo-irmão é estabelecida entre Arthrotardigrada e Echiniscoidea (KRISTENSEN \& HigGINS, 1984a).

CHRIstOFFERSEN \& AssunçÃo (no prelo), em seu novo sistema, propuseram relações de parentesco que modificam consideravelmente as relações aceitas previamente para os níveis superiores de Tardigrada. Como conseqüência, sugere-se aqui um diferente arranjo de grupos-externos, e alcançam-se diferentes resultados com 
respeito à polaridade e generalidade de caracteres, em comparação àqueles de BELLO \& De Zio GRimaldi (1998) (Fig. 5, Tabs 5 e 6).

\subsection{Digitopoda}

Conforme discutido anteriormente, CHRISTOFFERSEN \& AsSUnÇão (no prelo) reuniram, em Digitopoda: Halechisniscidae, os táxons Renaudarctidae e Batillipedidae, previamente utilizados como grupos externos aos halequiniscídeos, além do digitiforme Neostygarctus.

Das 148 espécies primariamente marinhas de Tardigrada, a maioria (87 espécies) está concentrada no táxon Halechiniscidae Thulin, 1928 (Tab. 4). Este é caracterizado tradicionalmente pela ausência de placas dorsais segmentares fortemente esclerotizadas, mais a presença de uma série completa de apêndices sensoriais cefálicos (em alguns casos, secundariamente incompletos) e pernas com quatro dígitos portando garras e/ou estruturas adesivas em forma de espátulas, entre outros.

Várias hipóteses, nenhuma delas com base no método cladístico, foram propostas para os subgrupos de Halechiniscidae (RENAUD-MoRNANT, 1984; 1987; KRISTENSEN \& Renaud-Mornant, 1983; Kristensen \& Higgins, 1984b; Pollock, 1995). Em sua abordagem, RENAUD-MORNANT (1984) utilizou critérios subjetivos para a criação de uma árvore filogenética, na qual os caracteres usados para agrupar os membros de Halechiniscidae constituem-se em simplesiomorfias. É também o caso do artigo de POLlOCK (1995), que propõe uma nova subfamília e, para justificar sua inclusão em Halechiniscidae, revê as relações filogenéticas entre os seus membros, relações essas expressas em um cladograma com oito táxons terminais ao nível de subfamílias (Fig. 4). Apesar do incontestável esforço em clarificar as tendências evolutivas dentro de 
Halechiniscidae, PoLlock (1995: 233) listou vários caracteres simplesiomórficos para o nível de generalidade desta família, deixando em aberto a discussão de seu monofiletismo.

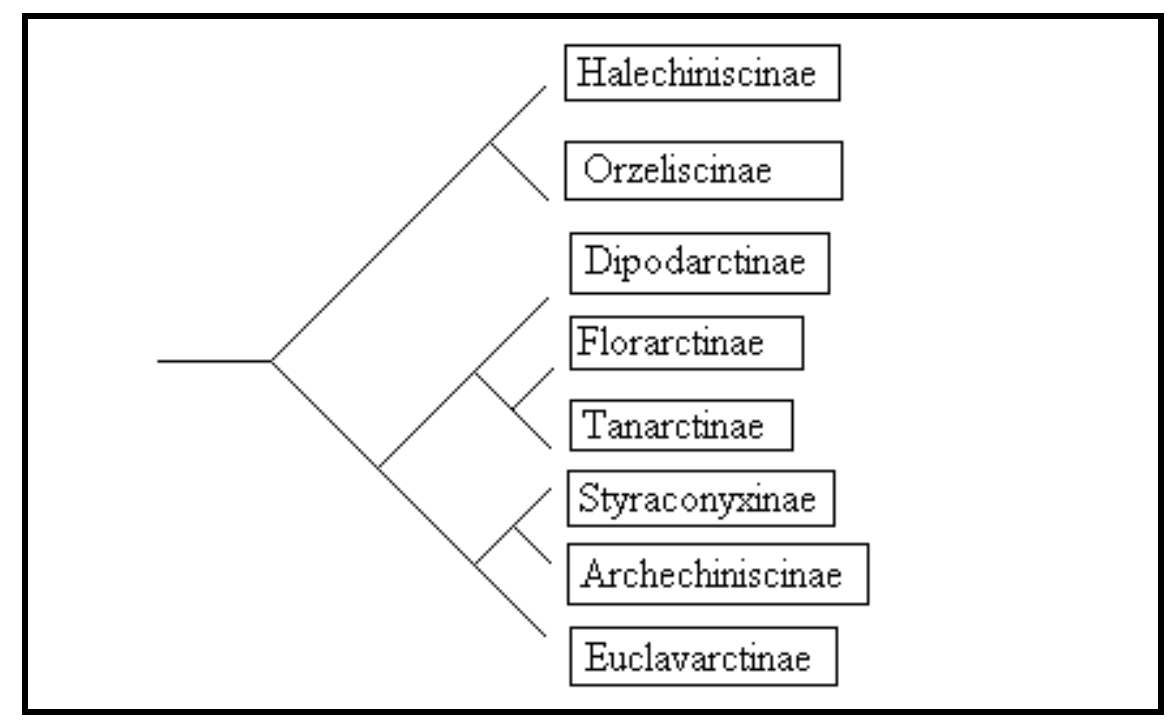

Figura 4 - Relações filogenéticas propostas para Halechiniscidae por Pollock (1995).

Tabela 4 - Lista dos táxons de Halechiniscidae atualmente aceitos. Os 29 gêneros de Halechiniscidae estão numerados em algarismos romanos; as 87 espécies estão numeradas em algarismos arábicos.

Fam. HALECHINISCIDAE Thulin, 1928

Subfam. Halechiniscinae Thulin, 1928

Gênero - tipo:

I - Halechiniscus Richters, 1908

Espécie - tipo:

1. H. guiteli Richters, 1908

Outras espécies:

02. H. chafarinensis Grimaldi De Zio \& Villora-Moreno, 1995

03 H. greveni Renaud-Mornant \& Deroux, 1976

04. H. macrocephalus Grimaldi De Zio, D'Addabbo Gallo \& Morone De Lucia, 1988

05. H. paratuleari Grimaldi De Zio, D'Addabbo Gallo \& Morone De Lucia, 1988

06. H. perfectus Schulz, 1955

07. H. remanei Schulz, 1955

H. remanei antillensis Renaud-Mornant, 1984

08. H. tuleari Reanud-Mornant, 1979

II - Chrysoarctus Renaud-Mornant, 1984

Espécie - tipo:

09. C. briandi Renaud-Mornant, 1984

Outras espécies:

10. C. flabelatus (Grimaldi De Zio, D'Addabbo Gallo, Morone De Lucia, Vacarella \& Grimaldi, 1982) Halechiniscus flabelatus Grimaldi De Zio, D'Addabbo Gallo, Morone De Lucia, Vacarella \& Grimaldi, 1982

III - Paradoxipus Kristensen \& Higgins, 1989

Espécie - tipo:

11. P. orzeliscoides Kristensen \& Higgins, 1989

Subfam. Orzeliscinae Schulz, 1963 
Gênero - tipo:

IV - Orzeliscus Bois-Reymond Marcus, 1952

Espécie - tipo:

12. O. belopus Bois-Reymond Marcus, 1952

O. septentrionalis Schulz, 1953

V - Opydorscus Renaud-Mornant, 1990 [1989]

Espécie - tipo:

13. O. fonsecae Renaud-Mornant, 1990 [1989]

Subfam. Dipodarctinae Pollock, 1995

Gênero - tipo:

VI - Dipodarctus Pollock, 1995

Hemitanarctus De Zio Grimaldi, D'Addabbo Gallo, Morone De Lucia \& Troccoli, 1996[1995]

Espécie - tipo:

14. D. borrori Pollock, 1995

Hemitanarctus chimaera De Zio Grimaldi, D'Addabbo Gallo, Morone De Lucia \& Troccoli, 1996[1995]

Outras espécies:

15. D. anaholiensis Pollock, 1995

16. D. subterraneus (Renaud-Debyser, 1959)

Halechiniscus subterraneus Renaud-Debyser, 1959

Subfam. Florarctinae Renaud-Mornant, 1982

Gênero - tipo:

VII - Florarctus Delamare-Deboutteville \& Renaud-Mornant, 1966 [1965]

Espécie - tipo:

17. F. heimi Delamare-Deboutteville \& Renaud-Mornant, 1966 [1965]

Outras espécies:

18. F. acer Renaud-Mornant, 1990

19. F. antillensis Van Der Land, 1968

20. F. asper Renaud-Mornant, 1990

21. F. cervinus Renaud-Mornant, 1987

22. F. cinctus Renaud-Mornant, 1976

23. F. glareolus Noda, 1987

24. F. hulingsi Renaud-Mornant, 1976

25. F. kwoni Chang \& Rho, 1997

26. F. pulcher De Zio Grimaldi, Lamarca, Gallo D'Addabbo \& Pietanza, 1999

27. F. salvati Delamare-Deboutteville \& Renaud-Mornant, 1966 [1965]

28. F. stellatus Renaud-Mornant, 1990 [1989]

29. F. vulcanius Renaud-Mornant, 1987

VIII - Wingstrandarctus Kristensen, 1984

Espécie - tipo:

30. W. corallinus Kristensen, 1984

Outras espécies:

31. W. crypticus Renaud-Mornant, 1990

32. W. intermedius (Renaud-Mornant, 1967)

Halechiniscus intermedius Renaud-Mornant, 1967

IX - Ligiarctus Renaud-Mornant, 1982

Espécie - tipo:

33. L. eastwardi Renaud-Mornant, 1982

Subfam. Tanarctinae Renaud-Mornant, 1980

Gênero - tipo:

X - Tanarctus Renaud-Debyser, 1959

Espécie - tipo:

34. Tanarctus tauricus Renaud-Debyser, 1959

Outras espécies:

35. T. arborspinosus Lindgren, 1971

36. T. dendriticus Renaud-Mornant, 1980

37. T. gracilis Renaud-Mornant, 1980

38. T. helleouetae Renaud-Mornant, 1984

39. T. heterodactylus Renaud-Mornant, 1980

40. T. longisetosus Grimaldi de Zio, D'Addabbo Gallo, Morone De Lucia, Vaccarella \& Grimaldi, 1982 
41. T. minotauricus Renaud-Mornant, 1984

42. T. ramazzotti Renaud-Mornant, 1975

43. T. velatus McKirdy, Schmidt \& McGinty-Bayly, 1976

XI - Actinarctus Schulz, 1935

Espécie - tipo:

44. A. doryphorus Schulz, 1935

A. doryphorus ocellatus Renaud-Mornant, 1971

Outras espécies:

45. A. lyrophorus Renaud-Mornant, 1979

46. A. neretinus Grimaldi De Zio, D'Addabbo Gallo, Morone De Lucia, Vacarella \& Grimaldi, 1982

47. A. physophorus Grimaldi De Zio, D’Addabbo Gallo, Morone De Lucia, Vacarella \& Grimaldi, 1982

XII - Zioella Renaud-Mornant, 1987

Espécie - tipo:

48. Z. pavonina Renaud-Mornant, 1987

Subfam. Styraconyxinae Kristensen \& Renaud-Mornant, 1983

Gênero - tipo:

XIII - Styraconyx Thulin, 1942

Espécie - tipo:

49. S. haplocerus Thulin, 1942

Outras espécies:

50. S. craticuliformis Chang \& Rho, 1998

51. S. craticulus (Pollock, 1983)

Bathyechiniscus craticulus Pollock, 1983

52. S. hallasi Kristensen, 1977

53. S. kristenseni Renaud-Mornant, 1981

S. sargassi Thulin, 1942 - parte

S. kristenseni neocaledonensis Renaud-Mornant, 1981

54. S. nanoqsunguak Kristensen \& Higgins, 1984

55. S. paulae Robotti, 1971

56. S. qivitoq Kristensen \& Higgins, 1984

57. S. sardinie D'Addabbo Gallo, Morone De Lucia \& Grimaldi De Zio, 1989

58. S. sargassi Thulin, 1942

59. S. testudo D'Addabbo Gallo, Grimaldi De Zio \& Morone De Lucia, 1984

60. S. tyrrhenus D'Addabbo Gallo, Morone De Lucia \& Grimaldi De Zio, 1989

XIV - Angursa Pollock, 1979

Espécie - tipo:

61. A. bicuspis Pollock, 1979

Outras espécies:

62. A. abyssalis Renaud-Mornant, 1981

A. bicuspis abyssalis Renaud-Mornant, 1981

63. A. antarctica Villora-Moreno, 1998

64. A. capsula Bussau, 1992

65. A. clavifera Noda, 1985

A. bicuspis clavifera Noda, 1985

66. A. lanceolata Renaud-Mornant, 1981

67. A. lingua Bussau, 1992

XV - Lepoarctus Kristensen \& Renaud-Mornant, 1983

Espécie - tipo:

68. L. coniferus (Renaud-Mornant, 1975)

Pleocola conifera Renaud-Mornant, 1975

XVI - Pleocola Cantacuzène, 1951

Espécie - tipo:

69. P. limnoriae Cantacuzène, 1951

XVII - Raiarctus Renaud-Mornant, 1981

Espécie - tipo:

70. R. colurus Renaud-Mornant, 1981

Outras espécies:

71. R. aureolatus Renaud-Mornant, 1981

72. . variabilis D’Addabbo Gallo, Grimaldi De Zio \& Morone De Lucia, 1986 
XVIII - Rhomboarctus Renaud-Mornant, 1984 [1983]

Espécie - tipo:

73. R. thomassini Renaud-Mornant, 1984 [1983]

XIX - Tetrakentron Cuénot, 1893 [1982]

Espécie - tipo:

74. T. synaptae Cuénot, 1893 [1982]

XX - Bathyechiniscus Steiner, 1926

Espécie - tipo:

75. B. tetronyx Steiner, 1926

XXI - Tholoarctus Kristensen \& Renaud-Mornant, 1983

Espécie - tipo:

76. T. natans Kristensen \& Renaud-Mornant, 1983

T. natans pedunculatus D’Addabbo Gallo, Grimaldi De Zio, Morone \& Troccoli, 1992

XXII - Paratanarctus D’Addabbo Gallo, Grimaldi De Zio, Morone De Lucia \& Troccoli, 1992

Espécie - tipo:

77. P. kristenseni D'Addabbo Gallo, Grimaldi De Zio, Morone De Lucia \& Troccoli, 1992

Subfam. Archechiniscinae Binda, 1978

Gênero - tipo:

XXIII - Archechiniscus Schulz, 1953

Espécie - tipo:

78. A. marci Schulz, 1953

Outras espécies:

79. A. minutus Grimaldi De Zio \& D'Addabbo Gallo, 1987

80. A symbalanus Chang \& Rho, 1998

Subfam. Euclavarctinae Renaud-Mornant, 1983

Gênero - tipo:

XXIV - Euclavarctus Renaud-Mornant, 1975

Espécie - tipo:

81. E. thieli Renaud-Mornant, 1975

Outras espécies:

82. E. convergens Renaud-Mornant, 1983

XXV - Clavarctus Renaud-Mornant, 1983

Espécie - tipo:

83. C. falculus Renaud-Mornant, 1983

XXVI - Exoclavarctus Renaud-Mornant, 1983

Espécie - tipo:

84. E. dineti Renaud-Mornant, 1983

XXVII - Proclavarctus Renaud-Mornant, 1983

Espécie - tipo:

85. P. fragilis Renaud-Mornant, 1983

XXVIII - Parmursa Renaud-Mornant, 1984

Espécie - tipo:

86. P. fimbriata Renaud-Mornant, 1984

XXIX - Mobjergarctus Bussau, 1992

Espécie - tipo:

87. M. manganis Bussau, 1992

Renaudarctidae foi considerada por KRISTENSEN \& HigGins (1984a) como grupoirmão de Stygarctidae, proposta esta mantida por BELLo \& DE ZIo GRIMALDI (1998) em sua filogenia para os gêneros de Stygarctidae (Fig. 3). Esta hipótese não foi sustentada no estudo de CHRISTOFFERSEN \& AssunÇão (no prelo), que consideram a presença de dígitos como um evento de origem única entre os tardígrados marinhos, 
conseqüentemente posicionando Digitopoda, e não somente Renaudarctidae, como grupo-irmão de Stygarctidae (Fig.1).

Outro táxon digitiforme é o monotípico Batillipedidae, tradicionalmente considerado como um grupo primitivo. Os dígitos de Batillipes são únicos, tanto em número quanto na forma, e foram interpretados por CHRISTOFFERSEN \& ASSUNÇão (no prelo) como derivados de uma linhagem de halequiniscídeos intersticiais com estruturas adesivas nos dígitos. Tais estruturas permitem-lhes agarrar-se ao substrato.

Quanto à Neostygarctus, originalmente incluído em Stygarctidae por DE ZIO GRIMALDI et al. (1982), DE ZIO GRIMALDI et al. (1987) não consideraram dígitos as estruturas que suportam as garras nesse táxon, argumentando que seriam completamente diferentes dos dígitos de Halechiniscidae, Renaudarctidae e Batillipedidae. Com base na hipótese de homologia primária (DE PINNA, 1991), CHRISTOFFERSEN \& ASSUNÇÃo (no prelo) entendem que a própria definição de dígitos (prolongamentos cuticulares sustentando garras) inclui também os dígitos de Neostygarctus e, portanto, consideram-no como um táxon basal de Digitopoda.

A análise dos 32 gêneros de Digitopoda no presente estudo resultou em uma nova proposta para as relações internas das sub-famílias desse táxon, a qual não corrobora o monofiletismo de Halechiniscidae e, portanto, não conserva arranjos previamente considerados na literatura (Figs 6 e 7, Tabs7 e 8).

\subsubsection{Comentários sobre as relações filogenéticas em Orzeliscinae Schulz, 1963}

A história do conhecimento dos membros de Orzeliscinae teve início no Brasil: Orzeliscus belopus foi dragado do infralitoral da ilha de São Sebastião, estado de São Paulo. Orzeliscus foi caracterizado pela presença de terminações digitiformes únicas, 
ou seja, 'estruturas adesivas em forma de espátulas nos dígitos', e pela ausência de garras. Outros caracteres tradicionais, como 'presença de cirro médio' e ‘presença de pedestal comum ao cirro lateral e à clava primária', todos apêndices sensoriais cefálicos, também foram utilizados na diagnose do gênero (DU BoIs-REYMOND MARCUS, 1952).

SCHUlz (1953) descreveu Orzeliscus septentrionalis de material proveniente do mar do Norte, baseando-se em algumas diferenças observadas entre esses espécimes e os espécimes conhecidos de O. belopus. Essa proposta foi discutida por McKIRDY et al. (1976) e, mais tarde, invalidada por Pollock (1982), que passa a considerar $O$. septentrionalis como sinônimo de O. belopus. Em suas considerações, PoLlock (1982) não mencionou o táxon Orzeliscidae, rebaixado para Orzeliscinae por RENAUD-MORNANT (1984) e, mais tarde, posicionado como grupo-irmão de Halechiniscinae por POLLOCK (1995).

Paradoxipus orzeliscoides, coletado na costa leste da Flórida, possui a combinação de garras mais a presença de 'estruturas adesivas em forma de espátulas’ na base dos dígitos. Tais estruturas foram consideradas homólogas àquelas observadas em Orzeliscus mas, por compartilhar também outros caracteres com o gênero Chrysoarctus, Paradoxipus foi contraditoriamente incluído em Halechiniscinae (KRISTENSEN \& HIGGINS, 1989).

Concomitantemente, Opydorscus fonsecae, um interessante tardígrado coletado na plataforma continental de Pernambuco, encaixou-se perfeitamente entre os caracteres diagnósticos de Orzeliscinae, com exceção da perda total de garras, pois as fêmeas deste gênero conservam a combinação das estruturas encontradas em Paradoxipus apenas no primeiro par de pernas. RENAUD-MORNANT (1989) chamou atenção para o dimorfismo sexual de Opydorscus, que apresenta diferentes estados evolutivos do 
aparelho locomotor: o macho reúne mais caracteres apomórficos que a fêmea (i.e., no macho faltam as garras nas terminações digitiformes). RENAUD-MORNANT (1989) também discutiu o fenômeno da perda de garras entre os Orzeliscinae. Entretanto, devido à simultaneidade desse estudo e do estudo conduzido por KRISTENSEN \& HigGINS (1989), foi estabelecida uma classificação equivocada para os subgrupos de Halechiniscinae e Orzeliscinae, permanecendo incompleta a história evolutiva desses grupos.

Neste trabalho foi reconstituída a série de transformação envolvendo os dígitos de Paradoxipus, Opydorscus e Orzeliscus, recuperando-se, assim, as relações filogenéticas entre esses gêneros (Fig. 8, Tab. 9). 


\section{OBJETIVOS}

Em decorrência do novo sistema proposto para os subgrupos de Tardigrada (CHRISTOFFERSEN \& AssunÇão, no prelo), surgiu a necessidade de se ajustar o tema de estudo da tese que visava, inicialmente, as relações filogenéticas entre os subgrupos de Halechiniscidae e Stygarctidae. No novo esquema, táxons como Neostygarctidae, Renaudarctidae e Batillipedidae, anteriormente considerados como externos aos táxons em estudo, passaram a fazer parte de um dos grupos internos, i.e., Digitopoda. Neoarctus, definitivamente desvinculado de Stygarctidae, serviu como grupo externo a Macrocephala, que passou a ser o objeto de estudo principal deste trabalho.

Assim, pretendeu-se testar o monofiletismo de "Halechiniscidae”, definir os grupos monofiléticos de Digitopoda e propor uma hipótese de relações de parentesco entre esses grupos, além de testar também o monofiletismo de Stygarctidae e de propor uma hipótese alternativa de interrelações entre os seus subgrupos.

As hipóteses aqui apresentadas contribuem para o conhecimento acerca da evolução das estruturas morfológicas nos grupos basais de Tardigrada, assim como para a construção de um sistema de referência desses táxons. 


\section{MATerial e MÉtodos}

A obtenção das informações, basicamente sobre estruturas morfológicas dos táxons, foi feita por meio de consulta à literatura especializada e também através da observação de espécimes biológicos.

O equipamento óptico utilizado para a observação de espécimes constou de um microscópio biológico trinocular da marca Olympus, modelo CH30-III, com acessório de câmara clara para desenho e contraste de fase para objetiva de 100x.

\subsection{Material biológico examinado}

Foram obtidos por empréstimo lotes de lâminas da coleção de tardígrados do National Museum of Natural History, Smithsonian Institution, EUA. Segue-se a listagem desse material:

\section{Stygarctidae:}

1- Megastygarctides orbiculatus: W53276 (holótipo), W53277 e W53278 (parátipos);

2- Parastygarctus higginsi: W62022;

3- P. sterreri: W62016;

4- Pseudostygarctus triungulatus: W53279 (holótipo), W53280 e W53281

(parátipos);

5- Stygarctus abornatus: W53274 (holótipo), W53275 (parátipo);

6- S. gourbaultae: W62017;

7- S. granulatus: W43098 (holótipo). 


\section{Digitopoda:}

1- Actinarctus doryphorus: W58810, W58811, W58812, W58813, W58814, W58815, W58816, W58817 e W58818 (parátipos);

2- Angursa bicuspis: W50900 (holótipo);

3- Bathyechiniscus (=Styraconyx) craticulus: W68683 (holótipo), W68684, W68685 e W68686 (parátipos);

4- Dipodarctus borrori: W264029 (holótipo) e W264030 (parátipo);

5- D. anaholiensis: W264027 (holótipo) e W264028 (parátipo);

6- Euclavarctus thieli: W62018;

7- Florarctus antillensis: W62024;

8- F. cinctus: W62019 e W62020;

9- F. hulingsi: W62021;

10- Halechiniscus greveni: W620225;

11- H. (= Wingstrandarctus) intermedius: W58946, W58947, W58948 e W58949;

12- H. remanei: W38977 e W38978

13- Orzeliscus belopus: W62026;

14- Renaudarctus psammocryptus: W81199 (holótipo) e W81200 (parátipo);

15- Styraconyx nanoqsunguak: W81187, W81188, W81189, W81190 e W81191 (parátipos);

16- S. qivitok: W81192, W81193, W81194, W81195 e W81196 (parátipos);

17- S. sargassi: W81197 e W81198 (síntipos);

18- Tanarctus velatus: W53282 (holótipo);

19- Tholoarctus natans: W98869 (parátipo). 


\section{Grupos externos:}

1- Anisonyches diakidius: W62023 e W50901 (holótipo);

2- Echiniscoides higginsi: W98870 (holótipo);

3- E. sigismundi: W38946, W38947, W81004, W81005.

A organização dos dados contou também com a utilização de matrizes pictóricas, preparadas com cópias de ilustrações da literatura primária, tendo sido documentados todos os táxons estudados (grupos internos e externos).

\subsection{Metodologia}

As análises seguiram o método henniguiano clássico (HENNIG, 1965, 1966; WILEY, 1981; AMORIM, 1997), sempre sob o princípio da iluminação recíproca, que integra os vários aspectos desse tipo de método comparativo. O método de polarização utilizado foi o do grupo externo (HeNNIG, 1966; Wiley, 1981; WATROUS \& WHEELER, 1981; e MADDISON et al., 1984), formalizado mais recentemente por NIXON \& CARPENTER (1993).

A abordagem metodológica utilizada é qualitativa. Séries de transformação foram construídas para os caracteres cujas transições entre seus estados puderam ser claramente estabelecidas, obtendo-se as primeiras hipóteses de filogenia. Foram sendo adicionados novos caracteres, com o intuito de reforçar hipóteses preliminares ou mesmo produzir novos arranjos congruentes.

Foi utilizado o critério de parcimônia, sem escolher, necessariamente, a árvore estritamente mais curta com a hipótese mais parcimoniosa. O conceito de parcimônia 
é usado com a qualidade e congruência dos dados, não com a quantidade de passos evolutivos.

O estabelecimento criterioso da generalidade do caráter e da seqüência de grupos externos é um dos problemas fundamentais na análise filogenética e foi explicitamente defendido e exemplificado como o "método da generalidade do caráter” (MOURA \& Christoffersen, 1996: 100). Este aspecto foi levado em consideração no contexto do estudo atual em virtude das inconsistências que persistem nas abordagens evolutivas na sistemática de Tardigrada.

A utilização do programa de computador Hennig 86 (versão 1.5; FARRIS, 1989), rodado com o programa de interface para ambiente Windows Tree Gardener (RAMOS, 1997), permitiu testar a consistência interna dos dados obtidos. Os estados de caráter foram codificados em matrizes de Táxons X Caracteres (Tabs 6 e 8). Para o cálculo das árvores, os caracteres multiestado não foram ordenados, somente aqueles em que as séries de transformação propostas são confiáveis. O algoritmo escolhido para calcular árvores mais parcimoniosas foi o mhennig*, adicionando-se a opção de consensus para a obtenção das árvores de consenso (Figs 5 e 7).

A incorporação de alguns caracteres não-comparáveis à matriz de Táxons $X$ Caracteres foi necessária para a análise das relações de alguns grupos internos, mesmo com a impossibilidade de comparação dos estados desses caracteres nos grupos externos.

Conforme descrito em Almeida \& Christoffersen (2000), o procedimento de análise não foi dividido em fases pré- e pós-matrizes estanques. Alternativamente, os resultados das abordagens henniguiana clássica e numérica foram criticamente comparados, obtendo-se interpretações consideradas qualitativamente mais consistentes sobre as relações de parentesco dos grupos. 
Finalmente, foi utilizado o artifício do "grupo ${ }^{+}$" para os clados resolvidos (AMORIM, 1982) mas não denominados nos sistemas propostos para os grupos em estudo. Evitou-se, assim, a criação de nomes novos, contornando-se o problema criado pelo uso de categorias lineanas. Do mesmo modo, foram eliminados do sistema os nomes de táxons monotípicos, ilógicos. A opção por considerar táxons terminais com diferentes “status” nomenclaturais não interferiu na análise, pois esta preocupa-se com agrupamentos monofiléticos e não com a denominação dos táxons.

\subsection{Seqüências de grupos externos}

As seqüências de grupos externos utilizados para as análises de Stygarctidae e Digitopoda foram baseadas no esquema filogenético proposto por CHRISTOFFERSEN \& AssunÇÃo (no prelo) (Fig. 1).

No caso de Stygarctidae, os grupos externos considerados estão representados por todos os outros táxons de tardígrados recentes conhecidos. Assim, o primeiro grupo externo é Digitopoda (grupo irmão de Stygarctidae), subdividido em dois grupos monofiléticos principais: Neostygarctus ${ }^{+}$e Renaudarctus $^{+}$. Em seguida vem Prototardigrada, grupo irmão de Macrocephala, cujo táxon mais basal é Coronarctidae. Além deste, também estão incluídos em Prototardigrada os táxons marinhos Anisonyches e Echiniscoides (= Echiniscoididae), e os táxons primariamente continentais reunidos em Limnotardigrada. Por fim, utilizou-se também Neoarctidae, grupo posicionado na base do cladograma dos Tardigrada (Fig. 1).

O mesmo procedimento foi adotado para a análise de Digitopoda, com a diferença de que o primeiro grupo externo, neste caso, é representado por Stygarctidae (grupo irmão de Digitopoda). 


\subsection{Caracteres}

Utilizou-se a morfologia externa de adultos e larvas como fonte de caracteres. A ornamentação da cutícula, o número e a forma de dígitos e garras nas pernas, a forma e a disposição de apêndices sensoriais cefálicos e torácicos, foram os aspectos preponderantemente utilizados nas análises.

Foram selecionados 61 caracteres para Stygarctidae, dos quais 43 são binários e 18 são multiestado. Para Digitopoda foram analisados 40 caracteres, sendo 31 binários e 9 multiestado.

\subsection{Abreviação}

T1-3 - primeiro a terceiro segmento torácicos 


\section{RESUltados}

Seguem-se os resultados das análises de Stygarctidae e Digitopoda. Convencionouse apresentar, para cada táxon estudado, uma lista comentada de caracteres (seções 4.1 e 4.3) para facilitar a visualização desses caracteres nas figuras e tabelas apresentadas nas seções 4.2 e 4.4 .

A filogenia de Stygarctidae, ilustrada em um cladograma (Fig. 5), o sistema filogenético seqüenciado (Tab. 5) e a matriz de Táxons X Caracteres (Tab. 6), rodada no programa Hennig 86, estão reunidas na seção 4.2.

A filogenia de Digitopoda, ilustrada no cladograma da Fig. 6, o sistema filogenético seqüenciado (Tab. 7), a matriz de Táxons X Caracteres (Tab. 8) e a árvore de consenso (Fig. 7), os dois últimos resultados obtidos no programa Hennig 86, estão reunidos na seção 4.4 .

A maioria das descrições feitas nas seções 4.1 e 4.3 foi simplificada quando transcrita para o programa Hennig 86. Reversões não foram consideradas nas análises numéricas, sendo codificadas com 0 nas matrizes de Táxons X Caracteres.

A seção 4.4.1 reúne o cladograma (Fig. 8) e o sistema filogenético seqüenciado (Tab. 9) para Orzeliscinae. Optou-se por não incluir estes resultados nas figuras e tabelas de Digitopoda, deixando-os em separado, já que não foram resolvidas as relações entre os gêneros das demais sub-famílias de Digitopoda. Os comentários pertinentes à filogenia de Orzeliscinae estão apresentados na seção 5.2.1, que discute os caracteres contidos na proposta de interrelações entre os gêneros Paradoxipus, Opydorscus e Orzeliscus. Neste caso, não foi necessário o uso do programa Hennig 86, pois foram usados apenas dois caracteres, cada um com dois estados, na resolução da tricotomia. 


\subsection{Lista comentada de caracteres para Stygarctidae}

A seguir estão listados os estados de caracteres e séries de transformação usados na análise (A refere-se à condição plesiomórfica; B-F representam condições apomórficas sucessivas; reversões de caráter são indicadas pelas letras entre colchetes). Alguns caracteres são comentados principalmente para destacar dados novos, obtidos através da análise, comparando-os com os resultados de BELLO \& DE ZIO GRIMALDI (1998).

01. A. Larvas com três pares de pernas; B. com quatro pares TARDIGRADA.

Adultos fósseis de Tardigrada do Cambriano não são conhecidos. Por isso é impossível estabelecer a generalidade exata de vários caracteres de adultos conhecidos somente para os Tardigrada recentes. Uma lista de oito autapomorfias possíveis para os Tardigrada, algumas das quais podem ser estendidas para os PanTardigrada quando adultos do Cambriano forem descritos, estão listados em CHRISTOFFERSEN \& ASSUNÇÃO (no prelo).

02. A. Cutícula do corpo lisa ou finamente ornamentada com pontos; B. com pequenos grânulos refringentes espalhados pelas placas cuticulares, particularmente nas dorsais (POLLOCK, 1970) Stygarctus granulatus.

03. A. Espínulos dorsais ausentes nas expansões laterais das placas cuticulares; B. presentes (HIRUTA, 1985) Stygarctus spinifer.

04. A. Cutícula do corpo não esculpida; B. cutícula em forma de colméia (DE ZIO GRIMALDI et al., 1998) Pseudostygarctus mirabilis; 
C. cutícula com pequenas depressões regularmente arranjadas em linhas paralelas (GALLO D’ADDABBo et al., 2000) Pseudostygarctus apuliae.

05. A. Superfície do corpo lisa, sem cerdas; B. irregularmente coberta com cerdas (MORGAN \& O’REILLY, 1988) Megastygarctides setoloso.

06. A. Cabeça alongada, com dois pares de cirros localizados serialmente em cada lado da cabeça; B. região anterior cefálica encurvada ventralmente, de tal forma que os cirros cefálicos externos tornaram-se ventrais, enquanto os cirros cefálicos internos permaneceram no dorso cefálico ARCHAEOTARDIGRADA;

C. região anterior cefálica fortemente encurvada em sentido ventral, de modo que os cirros cefálicos internos tornaram-se ventrais e as clavas primárias e os cirros A, que estão localizados na cabeça em Macrocephala (ver caráter 31 desta lista), tornaram-se anteriores, dando uma aparência truncada à cabeça em vista dorsal .... Neostygarctus ${ }^{+}$. 07. A. Cabeça não dividida distintamente em duas regiões; B. dividida distintamente em porção ântero-ventral (contendo o cone bucal e os cirros internos) e porção póstero-dorsal (contendo os cirros externos mais as clavas secundárias, os cirros A mais as clavas primárias e o cirro médio) (DE ZIO GRIMALDI et al., 1988)

Parastygarctus.

08. A. Cabeça sub-retangular; B. hemisférica Mesostygarctus intermedius.

09. A. Divisão da cabeça por uma forte depressão cuticular transversal em dois lobos ausente; B. presente, o lobo ventral separado lateralmente do lobo posterior por um "espace cuticulaire aminci" (RENAUD-MORNANT, 1979)

Mesostygarctus intermedius.

10. A. Par de fortes depressões sinuosas (sulci) ausentes entre os lobos cefálicos anteriores e medianos pares;

B. presentes Pseudostygarctus.

11. A. Cabeça sem lobos distintos; B. com seis lobos MACROCEPHALA; 
[C]. sem lobos distintos Renaudarctus ${ }^{+}$

D. com cinco lobos (o par anterior fundido) Stygarctus e (Mesostygarctus + Pseudostygarctus) + Megastygarctides;

[E]. com seis lobos (uma fenda rasa mediana entre os lobos anteriores)

Stygarctus gourbaultae + S. lambertii;

F. com quatro lobos (os lobos anteriores e medianos fundidos) ........ Megastygarctides.

Em Macrocephala, infere-se que ocorreu uma fusão da placa torácica com a cabeça somando quatro segmentos cefálicos (ver caráter 31 desta lista). A divisão da cabeça em lobos provavelmente está associada a essa fusão de segmentos, que leva a um total de quatro apêndices sensoriais pares localizados na cabeça (o que não ocorre nos grupos externos, i.e., Neoarctus e Prototardigrada).

A condição D, representada por dois eventos independentes, poderia ser considerada alternativamente como uma sinapomorfia de Stygarctus e (Mesostygarctus + Pseudostygarctus) + Megastygarctides. Entretanto, esta decisão geraria um conflito com os caracteres 24B e 58 desta lista, sinapomórficos para Stygarctus + Parastygarctus.

As condições D e F, interpretadas como fusões diversas entre os lobos mais frontais da cabeça, são aqui consideradas como inclusivas, ou seja, F deriva de D. Da mesma forma, considera-se a reversão [E] derivada de D. Os dois eventos ocorrem independentemente.

12. A. Margem frontal da cabeça sem envoltório cuticular; B. envoltório cuticular frontal cefálico presente (DE ZIO GRIMALDI et al., 1998) .. Pseudostygarctus mirabilis. 13. A. Par de espinhos dorsais cefálicos, inseridos sobre os sulci e dirigidos anteriormente, ausentes; B. presentes (DE ZIO GRIMALDI et al., 1998) Pseudostygarctus mirabilis. 
14. A. Lobos cefálicos medianos curtos em relação aos demais lobos; B. alongados Parastygarctus renaudae ${ }^{+}$

15. A. Lobos cefálicos medianos estendendo-se lateralmente no adulto; B. encurvados ventralmente, ao redor do cone bucal Stygarctus gourbaultae + S. lambertii.

16. A. Lobos cefálicos posteriores estendendo-se lateralmente no adulto; B. encurvados ventralmente

Parastygarctus renaudae e Stygarctus gourbaultae + S. lambertii.

17. A. Proeminências (“cotovelos”) dorsais ausentes nos lobos cefálicos posteriores do adulto; B. presentes Parastygarctus;

[C]. cotovelos dorsais ausentes Parastygarctus sterreri.

De Zio Grimaldi et al. (1988: 351) mencionam que $P$. biungulatus possui cotovelos pouco evidentes e que $P$. higginsi possui uma leve proeminência nas projeções posteriores laterais cefálicas. Infere-se, portanto, que a presença dessas proeminências é autapomórfica para Parastygarctus, e a ausência delas em P. sterreri é uma reversão.

18. A. Projeções ausentes nos lobos cefálicos posteriores do adulto; B. uma projeção aguda e voltada para trás em cada lobo STYGARCTIDAE; C. duas projeções agudas e voltadas para trás em cada lobo ..... Stygarctus granulatus; [D]. projeções ausentes Mesostygarctus e Megastygarctides.

19. A. Envoltório cuticular afunilado ausente nas projeções dos lobos cefálicos posteriores do adulto;

B. presente Stygarctus abornatus ${ }^{+}$. 20. A. Processo agudo lateral, em frente ao cirro A e clava primária, e voltado para a frente em cada lado da cabeça, ausente; B. presente Mesostygarctus intermedius. 21. A. Cirróforo do cirro médio cefálico cônico; B. arredondado Neoarctus. 
A despeito das dúvidas de BELLo \& DE Zio GrimALDi (1998: 174, caráter 11) com relação à polaridade desse caráter, o mesmo foi mantido. Entretanto, considera-se aqui o cirróforo arredondado como autapomorfia de Neoarctus.

Outras diferenças na forma e tamanho do cirróforo médio consideradas por BELLO \& De ZIO GRIMALDI (1998: 174, caráter 11) são muito variáveis em Tardigrada e, portanto, não utilizáveis.

22. A. Clavas terciárias presentes; B. ausentes STYGARCTIDAE.

Em Digitopoda, as clavas terciárias estão presentes em vários táxons (KRISTENSEN \& Higgins, 1984a, 1989; NodA, 1985; Bussau, 1992; Gallo D’AdDABBo et al., 1999; e outros). Em Prototardigrada, elas foram indicadas para Cornechiniscus cf. holmeni (KRISTENSEN, 1987) e para Echiniscoides horning (MILLER \& KRISTENSEN, 1999). Adicionalmente, as áreas sensoriais achatadas ventrais de Coronarctus podem ser homólogas às clavas terciárias (CHRISTOFFERSEN \& ASSUNÇÃO, no prelo). Inferese, portanto, que essas estruturas foram perdidas independentemente em diversos subgrupos dessas maiores linhagens de Tardigrada, além de Stygarctidae (ver caráter 06 da lista de caracteres de Digitopoda).

23. A. Clavas terciárias localizadas na região cefálica posterior; B. localizadas na região cefálica anterior. ARCHAEOTARDIGRADA.

Em todos os táxons onde há ocorrência das clavas terciárias, exceto em Neoarctus primigenius, elas estão localizadas próximo aos outros apêndices sensoriais cefálicos e/ou ao cone bucal.

24. A. Clavas secundárias de paredes finas; B. espessas.

Mesostygarctus + Pseudostygarctus;

[C]. finas Pseudostygarctus triungulatus. 
BeLlo \& DE ZIo GrimAldi (1998: 174, caráter 14) indicaram clavas secundárias de paredes espessas também em Neostygarctus. Esta é uma autapomorfia desse gênero, a qual ocorre homoplasticamente, e não uma condição do grupo Neostygarctus ${ }^{+}$(ver caráter 08 da lista de caracteres de Digitopoda).

25. A. Clavas secundárias não desenvolvidas, tipo domo; B. em forma de bastão Parastygarctus + Stygarctus;

C. cilíndricas e levemente encurvadas Stygarctus abornatus ${ }^{+}$

D. hemisféricas (Mesostygarctus + Pseudostygarctus) + Megastygarctides.

A variabilidade da forma das clavas secundárias, tanto nos grupos internos quanto nos grupos externos ao estudo, é enorme. Infere-se que a forma tipo domo, mais comum entre os tardígrados marinhos, seja plesiomórfica. Os estados B e C, em que ocorre um alongamento e dobramento dessas clavas, são lineares. Em contrapartida, no estado D as clavas tornam-se globosas e, em alguns casos, com paredes espessas (ver caráter 24 desta lista).

Variações de forma das clavas secundárias ocorrem homoplasticamente em subgrupos de Digitopoda e de Prototardigrada, grupos que também apresentam variações ainda mais sofisticadas dessas clavas (ver caráter 09 da lista de caracteres de Digitopoda).

26. A. Cirróforo robusto sustentando o cirro A e a clava primária; B. reduzido a envoltório do cirro A e clava primária Renaudarctus $^{+}$

C. ausente STYGARCTIDAE e PROTOTARDIGRADA.

O cirróforo foi perdido independentemente em Digitopoda, no táxon apical Euclavarctinae (ver também o caráter 10 da lista de caracteres de Digitopoda).

27. A. Clava primária localizada posteriormente em relação ao cirro A; B. ventralmente Neoarctus e Megastygarctides. 
Contrariamente a BELLO \& DE ZIO GRIMALDI (1998), considera-se a clava primária localizada posteriormente em relação ao cirro A como simplesiomórfica.

A posição relativa da clava primária e do cirro A parece não ter muita importância filogenética, pois apresenta uma variabilidade considerável em Tardigrada.

28. A. Comprimento da clava primária duas vezes a sua largura; B. mais de duas vezes a sua largura Parastygarctus renaudae ${ }^{+} \mathrm{e}$ (Mesostygarctus + Pseudostygarctus) + Megastygarctides.

29. A. Clavas primárias em forma de bastão; B. ovóides Megastygarctides isounguis.

30. A. Clavas primárias em forma de bastão; B. globosas

Stygarctus lambertii.

31. A. Placa escapular do tronco; B. incorporada à cabeça MACROCEPHALA. CHRISTOFFERSEN \& ASSUNÇÃO (no prelo) concluíram que somente em Macrocephala as clavas primárias e os cirros A foram incorporados à cabeça. Dentre estes, nos táxons que possuem placas cuticulares, a placa escapular fundiu-se com a placa cefálica. Estigarctídeos têm uma placa cefálica, três placas torácicas e uma placa caudal.

Bello \& De Zio Grimaldi (1998: 173, caráter 7) acreditam que todos os tardígrados, com exceção de Neoarctus, têm as clavas primárias e os cirros A localizados no segmento cefálico e que, em Neoarctus, a placa escapular teria se fundido à primeira placa torácica. AsSUNÇÃO \& CHRISTOFFERSEN (1994), numa interpretação equivocada da série de transformação da segmentação do corpo em Tardigrada, haviam sugerido essa idéia. Porém, após reinterpretarem essa hipótese, considerando a condição plesiomórfica encontrada em Neoarctus (placa escapular localizada no tronco), concluíram que Macrocephala tem o tagma cefálico formado 
por quatro metâmeros com quatro apêndices sensoriais pares (um par de estiletes bucais com seus respectivos suportes e três pares de cirros com suas respectivas clavas) (CHRISTOFFERSEN \& ASSUNÇÃO, no prelo ).

32. A. Olhos ausentes; B. presentes ARCHAEOTARDIGRADA;

[C]. ausentes STYGARCTIDAE.

A polaridade desse caráter difere da polaridade considerada por BELLO \& DE ZIO GRIMALDI (1998: 174, caráter 16), que consideraram a presença de olhos como plesiomórfica. ChristOFFERSEn \& AsSUnção (no prelo) consideram os olhos dos Tardigrada, exceto em Neoarctus, como únicos. A ausência deles seria uma reversão. Tal reversão ocorre independentemente em subgrupos de Digitopoda, em Coronarctidae e táxons mais apicais de Prototardigrada (i.e., Oreellidae, Carphanidae e vários Eutardigrada), além de Stygarctidae.

33. A. Poros nas placas ventrais ausentes; B. presentes STYGARCTIDAE.

DE ZIO GRIMALDi et al. (1988: 351) afirmaram que esses poros estão presentes em toda a família, embora, muitas vezes, não estejam totalmente distintos.

34. A. Placas intersegmentares dorsais ausentes; B. duas placas presentes entre T1-2 e $\mathrm{T} 2-3$ STYGARCTIDAE;

C. três placas presentes entre T1-2, T2-3 e entre T3 e o segmento caudal Parastygarctus biungulatus;

[D]. ausentes Parastygarctus higginsi + P. sterreri;

E. quatro placas estreitas estendendo-se por toda a largura do corpo presentes entre o segmento cefálico e T1, T1-2, T2-3, T3 e o segmento caudal Megastygarctides.

Bello \& De Zio Grimaldi (1998: 173, caráter 3) não consideraram o número de placas intersegmentares, apenas a presença/ausência e a forma dessas placas. 
Em Renaudarctus, duas placas pares intersegmentares dorsais também ocorrem entre T1-2 e entre T2-3 (KRISTENSEN, R.M. \& HigGins, R.P. 1984a: 300, fig. 7).

35. A. Placas torácicas dorsais sem nervuras; B. com um a dois pares de nervuras longitudinais Stygarctus bradypus ${ }^{+}$.

36. A. Bordas laterais nas placas torácicas sem lobos; B. bilobadas (RENAUDMORNANT, 1981b) Megastygarctides isounguis.

37. A. Projeções cuticulares dorsais entre T2-3 ausentes; B. um par de projeções espinhosas, com terminação única Stygarctus spinifer;

C. um par de projeções espinhosas, com terminação bifurcada

Stygarctus bradypus ${ }^{+}$.

38. A. Lobos póstero-laterais sinuosos na primeira e segunda placas torácicas dorsais ausentes; B. presentes Stygarctus gourbaultae + S. lambertii.

39. A. Tronco sem projeções cuticulares laterais; B. com um par de projeções cuticulares MACROCEPHALA;

C. com dois pares de projeções cuticulares

.... Parastygarctus biungulatus, P. higginsi e Pseudostygarctus apuliae + P. mirabilis;

[D]. projeções cuticulares ausentes Megastygarctides.

As projeções laterais torácicas foram perdidas independentemente em táxons apicais de Digitopoda, onde também houve perda de placas cuticulares (ver caráter 15 da lista de caracteres de Digitopoda).

Considera-se aqui não somente a presença/ausência dessas projeções, como fizeram Bello \& De Zio Grimaldi (1998: 173, caráter. 4), mas também o seu número e forma (ver também os carateres 40 a 43 desta lista).

Pseudostygarctus mirabilis e P. apuliae, este último recentemente descrito (GALLO D’ADDABBO et al., 2000), apresentam placas cuticulares terminando em dois pares de 
processos laterais. Embora esses processos diferenciem-se dos processos encontrados em Parastygarctus biungulatus e em P. higginsi, convencionou-se considerá-los todos como um mesmo caráter de ocorrência homoplástica. No caso das espécies de Pseudostygarctus, esses processos estão ainda circundados por membranas cuticulares com nervuras (ver caráter 40 desta lista).

40. A. Membrana cuticular das projeções laterais do tronco não desenvolvida; B. fortemente desenvolvida, com nervuras ........ Pseudostygarctus apuliae + P. mirabilis. 41. A. Projeções cuticulares laterais do tronco espinhosas; B. corniformes e com membrana cuticular com nervuras Stygarctus abornatus ${ }^{+}$.

42. A. Processos denteados na margem anterior das projeções cuticulares laterais corniformes ausentes; B. processos denteados presentes (DE ZIO GrimALDI et al., 1988) Stygarctus gourbaultae + S. lambertii

43. A. Processos denteados das projeções cuticulares laterais corniformes sem microespinhos; B. com cinco microespinhos, anteriormente dirigidos, em T1 e quatro em T2 (RENAUD-MORNANT, 1981a). Stygarctus gourbaultae; C. com três microespinhos, anteriormente dirigidos, em T1-2 (DE ZIO GRIMALDI et al., 1988) Stygarctus lambertii.

44. A. Adultos com placa cuticular caudal inteira; B. subdividida dorsalmente em placas menores Stygarctus bradypus.

45. A. Placa cuticular caudal sem par de projeções anteriores; B. com par de projeções anteriores pontiagudas Parastygarctus biungulatus; C. com par de projeções anteriores obtusas

Stygarctus e Pseudostygarctus triungulatus.

POLLOCK (1970) não mencionou ou ilustrou essas estruturas, assim como as estruturas tratadas abaixo (caráter 46), ao descrever Stygarctus granulatus. Entretanto, 
presume-se que elas estejam presentes, sendo difícil visualizá-las. O material disponível limita-se ao holótipo, de condições precárias, e não há registro de novas ocorrências dessa espécie na literatura. Portanto, optou-se por inferir a presença dessas estruturas, com base nas observações feitas no holótipo, e esperar que novos exemplares dessa espécie venham a corroborar ou não as séries de transformação propostas aqui.

46. A. Placa cuticular caudal sem par de projeções medianas; B. com par de projeções medianas pontiagudas Parastygarctus biungulatus e Stygarctus spinifer;

C. com par de projeções medianas reniformes Stygarctus granulatus ${ }^{+}$.

47. A. Placa cuticular caudal sem par de projeções pontiagudas posteriores; B. com projeções pontiagudas posteriores

Parastygarctus biungulatus e Stygarctus granulatus ${ }^{+}$.

Renaudarctus possui um par de projeções caudais, de origem independente, que falta aos demais táxons de Renaudarctus ${ }^{+}$.

Projeções pontiagudas posteriores únicas, provavelmente de origem independente, também ocorrem em algumas espécies de Batillipes e de Halechiniscus, que não possuem placas (ver caráter 16 da lista de caracteres de Digitopoda).

48. A. Articulações telescópicas nas pernas ausentes; B. presentes

ARCHAEOTARDIGRADA.

Devido ao posicionamento basal de Neoarctus, inverteu-se a polaridade estabelecida por Bello \& De ZIO GRIMALdi (1998: 174, caráter 20) para as articulações telescópicas nas pernas. No entanto, a utilidade deste caráter é reduzida, já que ocorrem reduções independentes em táxons distantes - em Echiniscidae, por exemplo (KRISTENSEN, 1987). 
49. A. Apêndice sensorial da perna IV (papila coxal) com um longo espinho terminal; B. espinho terminal curto ou ausente ARCHAEOTARDIGRADA.

BeLlo \& De Zio GRIMALDi (1998: 175, caráter 26) consideraram sinapomórfica a forma bulbosa da papila coxal em Stygarctidae e Renaudarctidae. Entretanto, em Prototardigrada a papila coxal também é bulbosa em Echiniscoides, Oreella, e Echiniscidae, mas parece espiniforme nos táxons basais Coronarctidae e Anisonyches. Desta maneira, considerou-se de difícil interpretação filogenética a forma bulbosa da papila coxal.

50. A. Par de espinhos estreitos e aguçados abaixo da coxa da perna IV das fêmeas ausente; B. presente (RENAUD-MORNANT, 1970) Parastygarctus sterreri.

Este par de espinhos não ocorre nos espécimes machos, sendo de importância taxonômica questionável (McKIRDY et al., 1976: 24, fig. 6).

51. A. Perna IV do mesmo tamanho que as pernas I-III; B. muito maior que as pernas I-III, devido ao alongamento da coxa MACROCEPHALA;

[C]. coxa da perna IV distintamente encurtada Renaudarctus $^{+}$e Megastygarctides isounguis + M. setoloso.

Em Neostygarctus e em Halechiniscus, a coxa da perna IV também é alongada. Ela é reduzida independentemente dentro da linhagem de Neostygarctus.

52. A. Garras sem pedestais; B. garras com pedestais curtos Megastygarctides.

53. A. Dígitos ausentes nas garras; B. presentes, com a base geralmente espiralada DigITOPODA.

Neostygarctus não possui a base dos dígitos espiralada, e as garras presentes nos dígitos parecem menos encurvadas (“C”-shaped) do que no restante dos Digitopoda. Apesar dessas diferenças, acredita-se que os dígitos de Neostygarctus podem representar um estado primitivo na evolução dos dígitos em Digitopoda. Portanto, 
discorda-se de Bello \& DE Zio Grimaldi (1998: 175, caráter 22), que não consideram essas estruturas como dígitos verdadeiros.

54. A. Adulto com quatro garras nas pernas I-IV; B. com três garras

Neoarctus e Pseudostygarctus triungulatus;

C. com duas garras Parastygarctus biungulatus.

Na linhagem dos Prototardigrada, o número de garras em cada perna foi independentemente reduzido para três em Trogloarctus.

55. A. Adulto com quatro garras nas pernas I-IV; B. com quatro garras nas pernas IIII e com duas garras na perna IV Megastygarctides.

56. A. Garras das pernas I-IV sem esporão basal; B. com esporão basal

PROTOTARDIGRADA.

CHRISTOFFERSEN \& ASSUNÇÃO (no prelo) interpretaram os esporões basais de Coronarctidae, Anisonyches, Oreella, e vários Echiniscidae, como homólogos aos chamados ramos secundários ("secondary branch") de Parachela.

57. A. Garras nas pernas I-III de igual tamanho; B. garras da perna III mais curtas que aquelas das pernas I-II (MoRGAN \& O’REILLY, 1988) ....... Megastygarctides setoloso; C. garras das pernas II-III mais curtas do que as da perna I (MCKIRDY et al., 1976) ..... Megastygarctides orbiculatus.

58. A. Garras da perna IV mais longas do que aquelas das pernas I-III; B. de igual tamanho (RENAUD-MORNANT, 1981b) Megastygarctides isounguis.

59. A. Garras internas sem filamentos terminais longos; B. com filamentos

Parastygarctus + Stygarctus;

Renaudarctus possui filamentos relativamente longos em todas as garras, embora eles não pareçam tão longos como os filamentos das garras internas de Parastygarctus e Stygarctus (ver caráter 22 da lista de caracteres de Digitopoda). 
60. A. Presença de espinhos acessórios somente nas garras internas das pernas I-IV; B. em todas as garras das pernas I-IV

Pseudostygarctus triungulatus e Megastygarctides.

Bello \& De Zio GRIMALdi (1998: 175, caráter 24) generalizaram a forma de espinhos acessórios encontrados nas garras de tardígrados marinhos, considerando também os filamentos terminais de Stygarctidae, que são aqui separados em outro caráter (ver caráter 58 desta lista). Além disso, equivocaram-se ao incluir Pseudostygarctus no caráter, pois $P$. mirabilis e $P$. apuliae têm esses espinhos apenas nas garras internas. Pseudostygarctus triungulatus, apesar de só ter três garras em cada perna, foi aqui incluído, pois a quarta garra foi considerada como supostamente perdida.

61. A. "Ball and double-socket articulation" ausente no cirro E; B. Presente Mesostygarctus + Pseudostygarctus.

Articulações sanfonadas grosseiras a refinadas, e também inúmeras a poucas, estados considerados por BELLO \& DE ZIO GRIMADI (1998: 174, caráter 17), não são relevantes para a resolução interna de Stygarctidae. 


\subsection{Relações entre os táxons de Stygarctidae}

Na análise de BeLlo \& De Zio GrimAldi (1998), o monofiletismo de Stygarctidae foi baseado unicamente na posição posterior da clava primária em relação ao cirro A, considerada neste estudo como simplesiomórfica (ver caráter 27 da lista de caracteres de Stygarctidae). Uma nova hipótese para o monofiletismo desse táxon foi proposta por CHRISTOFFERSEN \& ASSUNÇÃo (no prelo), que reuniram as seguintes sinapomorfias: (1) clavas terciárias ausentes; (2) poros nas placas cuticulares ventrais; (3) olhos ausentes; e (4) ausência de cirróforo robusto sustentando a clava primária e o cirro A (Fig. 2, Tab. 2). Na proposta apresentada neste estudo, somam-se mais duas sinapomorfias: (5) uma projeção aguda e voltada para trás em cada lobo cefálico posterior do adulto; e (6) duas placas intersegmentares dorsais presentes entre T1-2 e T2-3 (Fig. 5, Tab. 5).

O cladograma da Figura 5 representa a filogenia de Stygarctidae, recuperada através da análise manual de 61 caracteres (43 binários e 18 multiestado), ilustrando também as relações deste táxon com os grupos externos utilizados (i.e., todos os outros táxons de Tardigrada). O consenso de duas árvores, obtidas com a utilização do algoritmo mhennig*, apresentou a mesma topologia para os 17 táxons terminais de Stygarctidae. No resultado numérico, foram computados 98 passos evolutivos, índice de consistência 0,77 e índice de retenção 0,82.

O clado dos Stygarctidae foi subdividido em dois ramos relativamente simétricos: os clados (Parastygarctus + Stygarctus) e (Mesostygarctus + Pseudostygarctus) + Megastygarctides. O primeiro deles, anteriormente proposto por BELLO \& DE ZIO GRIMALDI (1998), com duas autapomorfias: (1) clavas secundárias desenvolvidas, em forma de bastão; e (2) longos filamentos terminais nas garras internas. As 
autapomorfias de Parastygarctus e de Stygarctus estão indicadas na Tabela 5. O clado (Mesostygarctus + Pseudostygarctus) + Megastygarctides, proposto neste estudo, é justificado com três autapomorfias: (1) região cefálica dividida em cinco lobos; (2) clavas secundárias hemisféricas; e (3) comprimento das clavas primárias mais de duas vezes a sua largura. As autapomorfias de seus subgrupos estão indicadas na Tabela 5.

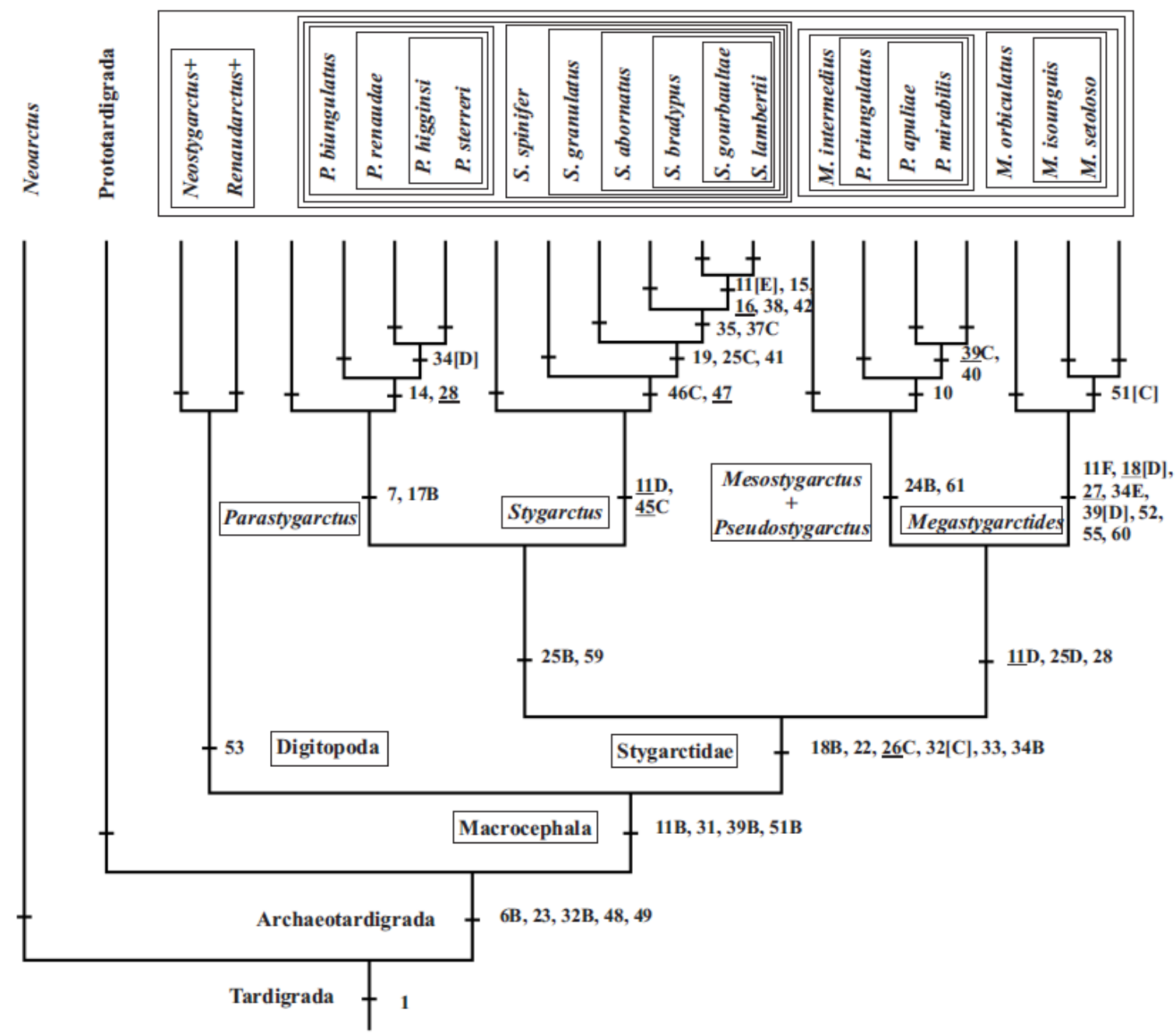

Figura 5 - Filogenia proposta para os 17 táxons terminais de Stygarctidae. Total de 101 passos evolutivos e índice de consistência 0,86. Somente nos nós principais foram indicadas sinapomorfias; caracteres grifados representam homoplasias; colchetes indicam reversões. 
Tabela 5 - Sistema filogenético seqüenciado para os subgrupos de Stygarctidae. Caracteres diagnósticos, baseados exclusivamente em apomorfias, estão indicados em negrito e entre chaves; colchetes indicam reversões.

Stygarctidae Schulz, 1951 \{18B, 22, 26C, 32[C], 33, 34B\}

Parastygarctus + Stygarctus Bello \& De Zio Grimaldi, 1998 \{25B, 59\}

Parastygarctus Renaud-Debyser, 1965 \{7, 17B

P. biungulatus De Lucia Morone, De Zio Grimaldi \& Gallo D’Addabbo, 1984 \{34C, 39C, 45B, 46B, 47, 54C\}

P. renaudae ${ }^{+}$, nov. $\{14,28\}$

P. renaudae De Zio Grimaldi, Gallo D’Addabbo, De Lucia Morone \& D’Addabbo, 1988 \{16\}

$P$. higginsi $+P$. sterreri, nov. $\{34[\mathrm{D}]\}$

P. higginsi Renaud-Debyser, 1965 (espécie tipo) \{39C\}

P. sterreri Renaud-Mornant, 1970 \{17[C], 50\}

Stygarctus Schulz, 1951 \{11D, 45C\}

S. spinifer Hiruta, 1985 \{3, 37B, 46B\}

S. granulatus ${ }^{+}$, nov. $\{46 \mathrm{C}, 47\}$

S. granulatus Pollock, 1970 \{2, 18C $\}$

S. abornatus ${ }^{+}$, nov. $\{19,25 \mathrm{C}, 41\}$

S. abornatus McKirdy, Schmidt \& McGinty-Bayly, 1976 \{?\}

S. bradypus ${ }^{+}$, nov. $\{35,37 \mathrm{C}\}$

S. bradypus Schulz, 1951 (espécie tipo) \{44\}

S. gourbaultae + S. lambertii, nov. \{11[E], 15, 16, 38, 42\}

S. gourbaultae Renaud-Mornant, 1981 \{43B\}

S. lambertii De Zio Grimaldi, Gallo D’Addabbo, De Lucia Morone \& D’Addabbo, 1988 \{30, 43C $\}$

(Mesostygarctus + Pseudostygarctus) + Megastygarctides, nov. \{11D, 25D, 28\}

Mesostygarctus + Pseudostygarctus Bello \& De Zio Grimaldi, 1998 \{24B, 61\}

Mesostygarctus Renaud-Mornant, 1979 \{8, 9, 18D, 20\}

M. intermedius Renaud- Mornant, 1979 (espécie tipo)

Pseudostygarctus McKirdy, Schmidt \& McGinty-Bayly, 1976 \{10\}

P. triungulatus McKirdy, Schmidt \& McGinty-Bayly, 1976 (espécie tipo) \{24C, 45C, 54B, 60\}

P. apuliae + P. mirabilis, nov. \{39C, 40\}

P. apuliae Gallo D’Addabbo, De Zio Grimaldi \& D’Addabbo, 2000 \{4C

P. mirabilis De Zio Grimaldi, Gallo D’Addabbo \& De Lucia Morone, 1998 \{4B, 12, 13\}

Megastygarctides McKirdy, Schmidt \& McGinty-Bayly, 1976 \{11F, 18[D], 27, 34E, 39[D], 52, 55, 60\}

M. orbiculatus McKirdy, Schmidt \& McGinty-Bayly, 1976 (espécie tipo) \{57C\}

M. isounguis + M. setoloso, nov. $\{\mathbf{5 1}[\mathrm{C}]\}$

M. isounguis Renaud-Mornant, 1981 \{29, 36, 58\}

M. setoloso Morgan \& O’Reilly, 1988 \{5, 57B\} 
Tabela 6 - Matriz e lista de 61 caracteres (47 binários e 14 multiestado) e 17 táxons terminais de Stygarctidae rodadas no programa Hennig 86. Algoritmo utilizado: mhennig*. (Grupos externos: Neoarc: Neoarctus; Protot: Prototardigrada; Gneost: grupo Neostygarctus ${ }^{+}$Grenau: grupo Renaudarctus $^{+}$; grupos internos: Pbiung: Parastygarctus biungulatus; Prenau: P. renaudae; Phiggi:P. higginsi; Psterr: P. sterreri; Sspini: Stygarctus spinifer; Sgranu: S. granulatus; Saborn: S. abornatus; Sbrady: S. bradypus; Sgourb: S. gourbaultae; Slambe: S. lambertii; Minter: Mesostygarctus intermedius; Ptriun: Psedostygarctus triungulatus; Papuli: P. apuliae; Pmirab: P. mirabilis; Morbic: Megastygarctides orbiculatus; Misoun: M. isounguis; Msetol: M. setoloso).

$\begin{array}{llllll}1 & 2 & 3 & 4 & 5 & 6\end{array}$

1234567890123456789012345678901234567890123456789012345678901

Neoarc1000000000000 - - - - 001000001000000000000 - - - - 000000000010000000

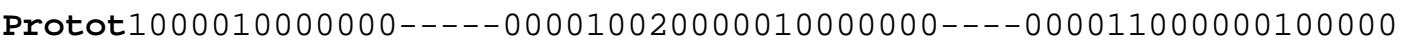

Gneost $10000200001000000000001000000011000000100--00001101010000000 \odot$

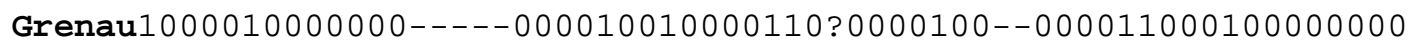

Pbiung10000110001000001100011012000010120000200 - - 011111010020000100

Prenau10000110001001011100011012010010110000100 - - 000011010000000100

Phiggi10000110001001001100011012010010?00000200 - - 000011010000000100

Psterr10000110001001000100011012010010100000100 - - 000011110000000100 Sspini10100100002000000100011012000010?10010100- - 021011010000000100

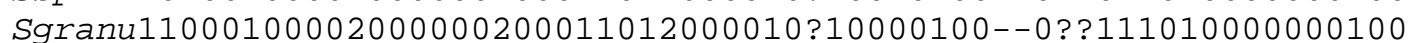
Saborn $10000100002000000110011022000010 ? 100001010-022111010000000100$ Sbrady $10000100002000000110011022000010 ? 110201010-122111010000000100$ Sgourb1000010000100011011001102200001011102110111022111010000000100

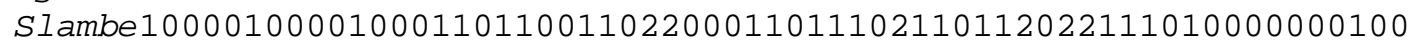
Minter 10000101102000000001011132010010110000100 - - 000011010000000001 Ptriun1000010001200000010001103?010010?10000100- - 020011010010000011 Papuli1002010001200000010001113?010010?10000210- - $0000 ? 1010000000001$ Pmirab1001010001211000010001113?010010110000210--000011010000000001 Morbic10000100003000000000011032110010?300000 - - - 000011011001020010

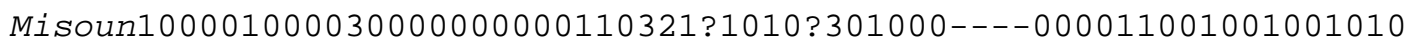

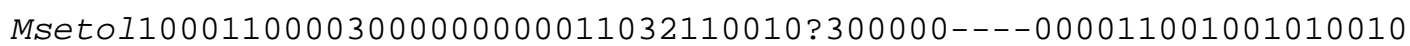

1. Larva

[0] com três pares de pernas; [1] com quatro pares de pernas;

2. Cutícula do corpo

[0] lisa ou finamente ornamentada com pontos; [1] com pequenos grânulos refringentes;

3. Espínulos dorsais nas expansões laterais das placas cuticulares [0] ausentes; [1] presentes;

4. Cutícula (não aditivo)

[0]não esculpida; [1] em forma de colméia; [2] com pequenas

depressões arranjadas em linhas paralelas;

5. Superfície do corpo irregularmente coberta com cerdas

[0] ausente; [1] presente;

6. Cabeça (aditivo)

[0] alongada; [1] encurvada ventralmente; [2] fortemente encurvada para baixo;

7. Divisão da cabeça em porção ântero-ventral e porção póstero-dorsal

[०] ausente; [1] presente;

8. Forma geométrica da cabeça

[0] sub-retangular; [1] hemisférica;

9. Divisão da cabeça por uma forte depressão cuticular transversal em dois lobos

[0] ausente; [1] presente;

10. Depressão sinuosa par (sulci) entre os lobos cefálicos anteriores e medianos pares

[0] ausente; [1] presente;

11. Número de lobos cefálicos (não aditivo)

[0] nenhum; [1] seis; [2] cinco; [3] quatro;

12. Envoltório cuticular frontal cefálico 
[0] ausente; [1] presente;

13. Espinho dorsal cefálico par inserido sobre os "sulci"

[0] ausentes; [1] presentes;

14. Lobos cefálicos medianos do adulto

[0] curtos; [1] alongados;

15. Lobos cefálicos medianos do adulto

[0] laterais; [1] encurvados ventralmente;

16. Lobos cefálicos posteriores do adulto

[0]laterais; [1] encurvados ventralmente

17. Proeminências ("cotovelos") dorsais nos lobos cefálicos

posteriores do adulto

[0] ausentes; [1] presentes;

18. Número de projeções agudas e voltadas para trás nos lobos

cefálicos posteriores do adulto (não aditivo)

[0] nenhuma; [1] uma projeção em cada lobo; [2] duas projeções em cada lobo;

19. Envoltório cuticular afunilado nas projeções dos lobos cefálicos posteriores do adulto

[0] ausentes; [1] presentes;

20. Processo agudo lateral cefálico, em frente ao cirro A e clava primária, voltado para a frente em cada lado da cabeça

[0] ausente; [1] presente;

21. Cirróforo do cirro médio cefálico

[๑] cônico; [1] arredondado;

22. Clavas terciárias

[0] presentes; [1] ausentes;

23. Posição das clavas terciárias na placa cuticular cefálica

[๑] na região posterior; [1] na região cefálica anterior;

24. Parede das clavas secundárias

[0] fina; [1] espessa;

25. Forma das clavas secundárias (não aditivo)

[0] não desenvolvidas, tipo domo; [1] claviformes; [2] cilíndricas e levemente encurvadas; [3] hemisféricas;

26. Cirróforo robusto sustentando o cirro A e a clava primária (não aditivo)

[๑] presente; [1] reduzido a envoltório do cirro A e clava primária;

[2] ausente;

27. Posição da clava primária em relação ao cirro $A$

[0] posterior; [1] ventral;

28. Comprimento das clavas primárias

[0] duas vezes a largura; [1] mais de duas vezes a largura;

29. Forma das clavas primárias

[๑] claviforme; [1] ovóide

30. Forma das clavas primárias

[0] claviforme; [1] globosa;

31. Localização da placa escapular

[0] no tronco; [1] incorporada à cabeça;

32. Olhos

[0] ausentes; [1] presentes;

33. Poros nas placas ventrais

[0] ausentes; [1] presentes;

34. Placas intersegmentares dorsais (não aditivo)

[0] ausentes; [1] duas placas; [2] três placas; [3] quatro placas presentes;

35. Número de nervuras nas placas torácicas dorsais

[๑] nenhuma; [1] um a dois pares de nervuras longitudinais;

36. Bordas laterais bilobadas nas placas torácicas

[0] ausentes; [1] presentes;

37. Par de projeções cuticulares dorsais entre T2-3 (não aditivo)

[0] ausente; [1] presente, com terminação única; [2] presente, com terminação bifurcada; 
38. Lobos póstero-laterais sinuosos na primeira e segunda placas torácicas dorsais

[0] ausentes; [1] presentes;

39. Número de projeções cuticulares laterais no tronco (não aditivo)

[0] ausentes; [1] presentes (um par); [2] presentes (dois pares);

40. Membrana cuticular das projeções laterais do tronco

[0] não desenvolvida; [1] fortemente desenvolvida, com nervuras;

41. Forma das projeções cuticulares laterais do tronco

[0] espinhosas; [1] corniformes e com membrana cuticular com nervuras;

42. Processos denteados na margem anterior das projeções cuticulares laterais corniformes

[0] ausentes; [1] presentes;

43. Processos denteados das projeções cuticulares laterais corniformes (não aditivo)

[0] sem microespinhos; [1] com 5 microespinhos em T-1 e 4 microespinhos em T-2; [2] com 3 microespinhos em T1-2;

44. Adultos com placa cuticular caudal

[0] inteira; [1] subdividida dorsalmente em placas menores;

45. Par de projeções anteriores da placa cuticular caudal (não aditivo)

[0] ausente; [1] presente, pontiagudas; [2] presente, obtusas

46. Par de projeções medianas da placa cuticular caudal (não aditivo)

[0] ausente; [1] presente, pontiagudas; [2] presente, reniformes

47. Par de projeções pontiagudas posteriores da placa cuticular

caudal

[0] ausente; [1] presente;

48. Articulações telescópicas nas pernas

[0] ausentes; [1] presentes;

49. Longo espinho terminal da papila sensorial da perna IV

[0] presente; [1] curto ou ausente;

50. Par de espinhos estreitos aguçados abaixo da coxa da perna IV das fêmeas

[0] ausente; [1] presente;

51. Tamanho da perna IV

[0] não alongada; [1] mais longa do que as pernas I-III;

52. Pedestais das garras nos tarsos das pernas I-IV

[0] ausentes; [1] presentes;

53. Dígitos

[0] ausentes; [1] presentes;

54. Número de garras nas pernas I-IV do adulto (não aditivo)

[๑] quatro; [1] três; [2] duas;

55. Número de garras nas pernas I-IV do adulto

[0] quatro; [1] quatro nas pernas I-III e duas na perna IV;

56. Esporão basal nas garras das pernas I-IV

[0] ausente; [1] presente;

57. Tamanho das garras das pernas I-III (não aditivo)

[0] igual; [1] garras da perna III menores do que as garras das

pernas I-II; [2] garras das pernas II-III menores do que as da perna I;

58. Tamanho das garras das pernas I-IV

[๑] garras da perna IV maiores do que as garras das pernas I-III; [1] igual;

59. Filamentos terminais longos nas garras internas das pernas I-IV

[0] ausentes; [1] presentes;

60. Espinhos acessórios nas garras

[0] somente nas garras internas; [1] em todas as garras;

61. "Ball and double-socket articulation" no cirro E

[0] ausente; [1] presente; 


\subsection{Lista comentada de caracteres para Digitopoda}

Abaixo estão listados os estados de caracteres e séries de transformação usados na análise (A refere-se à condição plesiomórfica; B-D representam condições apomórficas sucessivas; reversões de caráter são indicadas pelas letras entre colchetes). Os caracteres 01 a 22 referem-se a caracteres utilizados previamente na análise de Stygarctidae, os quais, após sofrerem alguns ajustes, foram utilizados nesta análise. Muitos deles já foram comentados na análise de Stygarctidae, tornando-se desnecessário repetí-los nesta lista.

01. A. Larvas com três pares de pernas; B. com quatro pares TARDIGRADA.

Ver comentários para o mesmo caráter na lista de caracteres de Stygarctidae.

02. A. Cabeça alongada, com dois pares de cirros localizados serialmente em cada lado da cabeça (= caráter 6 da lista de caracteres de Stygarctidae); B. região anterior cefálica encurvada ventralmente de tal forma que os cirros cefálicos externos tornaram-se ventrais, enquanto os cirros cefálicos internos permaneceram no dorso cefálico ARCHAEOTARDIGRADA;

C. região anterior cefálica fortemente encurvada em sentido ventral, de modo que os cirros cefálicos internos tornaram-se ventrais e as clavas primárias e os cirros A, que estão localizados na cabeça em Macrocephala (ver caráter 9), tornaram-se anteriores, dando uma aparência truncada à cabeça em vista dorsal Neostygarctus ${ }^{+}$.

03. A. Cabeça sem lobos distintos (= caráter 11, em parte, da lista de caracteres de Stygarctidae); B. com seis lobos conspícuos MACROCEPHALA;

[C]. sem lobos distintos Renaudarctus ${ }^{+}$

D. lobos anteriores e medianos reduzidos Neostygarctus ${ }^{+}$. 
04. A. Projeções agudas e voltadas para trás ausentes nos lobos cefálicos posteriores do adulto (= caráter 18, em parte, da lista de caracteres de Stygarctidae); B. uma projeção presente em cada lobo STYGARCTIDAE.

05. A. Cirróforo do cirro médio cefálico cônico (= caráter 21 da lista de caracteres de Stygarctidae); B. arredondado Neoarctus.

06. A. Clavas terciárias presentes (= caráter 22 da lista de caracteres de Stygarctidae); B. ausentes STYGARCTIDAE, Neostygarctus, Batillipes, Dipodarctus, EuclavarCTINAE.

07. A. Clavas terciárias localizadas na região cefálica posterior (= caráter 23 da lista de caracteres de Stygarctidae); B. localizadas na região cefálica anterior

ARCHAEOTARDIGRADA.

08. A. Clavas secundárias de paredes finas (= caráter 24 , em parte, da lista de caracteres de Stygarctidae);

B. espessas Neostygarctus.

09. A. Clavas secundárias não desenvolvidas, tipo domo (= caráter 25, em parte, da lista de caracteres de Stygarctidae); B. desenvolvidas, de formas variadas

..... StygARCtidAe, Neostygarctus, FlorARctinAe + TANARCTINAE e Renaudarctus.

Este caráter é de difícil análise, pois ocorrem muitas variações de formas das clavas secundárias a nível específico. Além disso, suspeita-se que, em diversos subgrupos de Digitopoda em que ocorrem clavas terciárias, tenha havido uma fusão das clavas secundárias e terciárias para formar estruturas sensoriais complexas, tais como as encontradas em Paradoxipus orzeliscoides e outros.

Em Prototardigrada, as áreas sensoriais achatadas dorsais de Coronarctus provavelmente são homólogas às clavas secundárias (CHRISTOFFERSEN \& ASSUNÇÃO, no prelo). Portanto, ocorrem homoplasticamente neste táxon, e não em Prototardigrada como um todo. 
10. A. Cirróforo robusto sustentando o cirro A e a clava primária (= caráter 26 da lista de caracteres de Stygarctidae); B. reduzido a envoltório do cirro A e clava primária Renaudarctus $^{+}$

C. ausente Prototardigrada, Stygarctidae e Euclavarctinae.

11. A. Placa escapular do tronco (= caráter 31 da lista de caracteres de Stygarctidae); B. incorporada à cabeça MACROCEPHALA.

12. A. Olhos ausentes (= caráter 32 da lista de caracteres de Stygarctidae); B. presentes ARCHAEOTARDIGRADA;

[C]. ausentes STYGARCTIDAE, Dipodarctus, FlorARCTINAE, Renaudarctus e EuClaVARCTINAE.

CHRISTOFFERSEN \& ASSUNÇÃO (no prelo) advertiram para a perda freqüente da presença de olhos nos diversos grupos de Tardigrada. Além disso, destacaram que o método e tempo de preservação dos espécimes podem impedir a observação de olhos, quando presentes. Assim, este é um caráter duvidoso, que requer a observação de mais espécimes, já que a literatura não fornece informação completa para uma análise mais criteriosa.

13. A. Poros nas placas ventrais ausentes (= caráter 33 da lista de caracteres de Stygarctidae);

B. presentes STYGARCTIDAE.

14. A. Placas intersegmentares dorsais ausentes (= caráter 34 , em parte, da lista de caracteres de Stygarctidae); B. duas placas presentes entre T1-2 e T2-3

STYGARCTIDAE e Renaudarctus.

15. A. Tronco sem projeções cuticulares laterais (= caráter 39, em parte, da lista de caracteres de Stygarctidae); B. com um par de projeções cuticulares MACROCEPHALA; 
[C]. Projeções cuticulares ausentes

Dipodarctus $^{+} \mathrm{e}$

EUCLAVARCTINAE + STYRACONYXINAE.

16. A. Projeção cuticular pontiaguda única ausente no segmento caudal; B. presente Batillipes e HALECHINISCINAE.

Projeções pares ocorrem nas placas cuticulares caudais de alguns estigarctídeos e em Renaudarctus (ver caráter 47 da lista de caracteres de Stygarctidae). Em Batillipes e Halechiniscus, táxons desprovidos de placas cuticulares, são comuns projeções únicas, geralmente acompanhadas de projeções cuticulares laterais caudais.

17. A. Articulações telescópicas nas pernas ausentes (= caráter 48 da lista de caracteres de Stygarctidae);

B. presentes ARCHAEOTARDIGRADA.

Em Styraconyxinae, faltam as articulações telescópicas nas pernas de Archechiniscus.

18. A. Apêndice sensorial da perna IV (papila coxal) com um longo espinho terminal (= caráter 49 da lista de caracteres de Stygarctidae); B. espinho terminal curto ou ausente ARCHAEOTARDIGRADA.

19. A. Perna IV do mesmo tamanho que as pernas I-III (= caráter 51 da lista de caracteres de Stygarctidae); B. muito maior que as pernas I-III, devido ao alongamento da coxa MACROCEPHALA;

[C]. coxa da perna IV distintamente encurtada Renaudarctus ${ }^{+}$.

20. A. Dígitos ausentes nas garras (= caráter 53 da lista de caracteres de Stygarctidae);

B. presentes, com a base geralmente espiralada DiGITOPODA.

Comentários pertinentes aos dígitos de Neostygarctus encontram-se na lista de caracteres de Stygarctidae.

21. A. Garras das pernas I-IV sem esporão basal (= caráter 56 da lista de caracteres de Stygarctidae); B. com esporão basal PrototardigRAdA. 
22. A. Garras internas sem filamentos terminais; B. com filamentos ..... Renaudarctus. Assumindo-se que os filamentos terminais de Parastygarctus + Stygarctus (= caráter 59 da lista de caracteres de Stygarctidae) e Renaudarctus têm ocorrência homoplástica, considera-se então que os filamentos em Renaudarctus são únicos, apomórficos somente para este táxon e excluindo os demais táxons de Renaudarctus ${ }^{+}$. 23. A. Dígitos sem membrana cuticular protetora cobrindo totalmente as garras; B. com membrana cuticular (HALECHINISCINAE + ORZELISCINAE $)^{+} \mathrm{e}$ EUCLAVARCTINAE + STYRACONYXINAE.

Especializações em dígitos combinados com garras são difíceis de polarizar, já que não há grupos externos a Digitopoda que apresentem tais estruturas (i.e., as condições tratadas nos caracteres 23 a 32 não são comparáveis nos grupos externos ao estudo).

A aquisição dessas membranas poderia ser considerada como única em Digitopoda, ao invés de dois eventos homoplásticos, como apresentado neste estudo. Entretanto, isso acarretaria a inclusão de mais dois passos evolutivos na análise, pois três reversões precisariam ser consideradas para Neostygarctus, Batillipes e Renaudarctus. Os dígitos de Batillipes são bastante especializados (ver caracteres 29 e 30 desta lista), enquanto Neostygarctus e Renaudarctus possuem dígitos com poucas especializações.

Estudos mais detalhados dos dígitos combinados com garras nesses dois últimos táxons poderiam esclarecer melhor a evolução deste caráter. De fato, as garras de Renaudarctus são diferentes de todas as outras em Tardigrada, pois apresentam uma porção fortemente cuticularizada (a garra propriamente dita?) e uma porção laminar translúcida (KRISTENSEN \& HIGGINS, 1984a), que poderia ser homóloga às membranas cuticulares protetoras. 
24. A. Dígitos internos nas pernas I-IV de igual tamanho ao dos dígitos externos; B. maior do que o dos dígitos externos Dipodarctus $^{+} \mathrm{e}$ EUCLAVARCTINAE + STYRACONYXINAE.

Em Archechiniscus, os dígitos externos tornaram-se vestigiais.

25. A. Padrão de comprimento dos dígitos das pernas I-III igual ao da perna IV; B. dígitos das pernas I-III com pelo menos três dos quatro dígitos curtos e de igual tamanho (POLLOCK, 1995) Dipodarctus.

26. A. Dígitos com pedúnculos; B. pedúnculos reduzidos a simples barras no tarso POLLOCK (1995) Dipodarctus;

C. pedúnculos ausentes Neostygarctus, Batillipes, HALECHINISCINAE + ORZELISCINAE, TANARCTINAE, Renaudarctus e EUCLAVARCTINAE.

Condição parecida à condição B verifica-se também em Archechiniscus.

Em Dipodarctus, faltam os pedúnculos em D. anaholyensis, evento homoplástico múltiplo observado nos diversos táxons listados acima. Em Styraconyxinae, Paratanarctus kristenseni também não possui pedúnculos nos dígitos; em contrapartida, há estruturas adesivas na base de todos os dígitos dessa espécie (ver caráter 28 desta lista).

27. A. Pedúnculos retilíneos nos dígitos; B. em forma de gancho na base dos dígitos FLORARCTINAE.

28. A. Base dos dígitos sem estruturas adesivas; B. com estruturas adesivas alongadas em todos os dígitos ORZELISCINAE; C. com estruturas adesivas cordiformes na base dos dígitos internos

STYRACONYXINAE.

Dentre os Styraconyxinae, Paratanarctus kristenseni é o único com estruturas adesivas ("basal pads”) em todos os dígitos, embora essas estruturas cordiformes 
restrinjam-se aos dígitos internos. A presença de “basal pads” normalmente está associada à ausência de pedúnculos nos dígitos (ver caráter 26 desta lista).

CHANG \& RHo (1998), ao descreverem Archechiniscus symbalanus, mencionam que os dígitos internos estão separados de suas bases por proeminentes pedestais. Não há referência à estruturas adesivas. Conclui-se, então, que as estruturas adesivas cordiformes foram perdidas secundariamente nessa espécie.

29. A. Extremidade dos dígitos sem estruturas adesivas; B. com discos adesivos Batillipes.

30. A. Quatro dígitos em cada perna do adulto; B. seis dígitos Batillipes. 31. A. Garras dos dígitos internos desprovidas de ganchos acessórios; B. com ganchos acessórios internos STYRACONYXINAE.

32. A. Garras desprovidas de ganchos de sustentação externos (“calcars”); B. com ganchos de sustentação, os quais se encontram inseridos na parte distal dos dígitos ..... Dipodarctus $^{+}$.

Em Halechiniscinae, Chrysoarctus também possui garras providas com “calcars”. É possível que essas estruturas possam ter sido negligenciadas em outras espécies de Halechiniscinae, assim como em Styraconyxinae (presentes em Paratanarctus).

33. A. Clavas primárias de tamanho menor ou igual que os cirros A; B. maior que os cirros A Dipodarctus $^{+}$.

34. A. Apêndices sensoriais da perna IV (papilas coxais) mais curtas que o corpo; B. mais longas que o corpo TANARCTINAE.

Além do alongamento, esses apêndices sofrem ramificações e diferenciações em suas extremidades, formando estruturas sensoriais complexas e vistosas em diversos subgrupos de Tanarctinae. 
35. A. Ornamentação da cutícula desprovida de longos pilares de sustentação da epicutícula; B. com pilares de sustentação que crescem de tamanho do centro para a periferia do corpo TANARCTINAE.

36. A. Cutícula desprovida de expansões aliformes; B. com expansões aliformes

FLORARCTINAE.

Expansões aliformes restritas à região caudal ocorrem em Chrysoarctus flabelatus e Paradoxipus orzeliscoides.

37. A. Suporte dos estiletes presentes; B. modificados em uma baínha cuticular envolvendo o bulbo faríngeo (DE ZIo GRIMALDI et al., 1992) Neoarctus;

C. ausentes STYGARCTIDAE, Neostygarctus, Renaudarctus e EuClAVARCTINAE.

Perdas independentes também ocorrem em Florarctinae e Tanarctinae.

38.A. Corpo cilíndrico; B. delgado EUCLAVARCTINAE + STYRACONYXINAE.

39. A. Ductos dos receptáculos seminais abrindo-se lateralmente; B. abrindo-se medianamente .... STYGARctidAe, HALECHINISCINAE + ORZELISCINAE, Renaudarctus.

Em Styraconyxinae, os ductos dos receptáculos seminais de Archechiniscus também se abrem medianamente.

Receptáculos seminais faltam em Chrysoarctus. Em táxons apicais de Prototadigrada, ocorre ou a redução de dois para apenas um receptáculo seminal ou a perda dessas estruturas (CHRISTOFFERSEN \& ASSUNÇÃO, no prelo).

40. A. Placas cuticulares espessadas dorsais e ventrais presentes; B. ausentes Batillipes $^{+}$e EUCLAVARCTINAE + STYRACONYXINAE.

Placas cuticulares espessadas também são perdidas em táxons apicais de Prototadigrada (CHRISTOFFERSEN \& AsSUnÇÃO, no prelo). 


\subsection{Relações entre os táxons de Digitopoda}

Na análise de CHRISTOFFERSEN \& AssunçÃo (no prelo), o monofiletismo de Digitopoda foi baseado unicamente na presença de dígitos sustentando cada garra (Fig. 2, Tab. 2). Essa proposta foi corroborada no presente trabalho, o qual apresentou uma filogenia totalmente resolvida para os táxons superiores de Digitopoda (Fig. 6, Tab. 7).

O cladograma da Figura 6 representa o resultado da análise manual de 40 caracteres para Digitopoda (31 binários e 9 multiestado), ilustrando também as relações deste táxon com os grupos externos utilizados (i.e., todos os outros táxons de Tardigrada). Digitopoda foi subdividido em dois grupos monofiléticos, ambos propostos neste estudo: Neostygarctus ${ }^{+}$e Renaudarctus ${ }^{+}$. O primeiro é justificado por duas autapomorfias, intimamente relacionadas: (1) região anterior cefálica fortemente encurvada em sentido ventral, com os cirros cefálicos internos posicionados ventralmente, e as clavas primárias e os cirros A localizados na região anterior cefálica, conferindo à cabeça uma aparência truncada em vista dorsal; e (2) lobos cefálicos anteriores e medianos reduzidos. O segundo grupo é justificado por três autapomorfias, sendo as duas últimas consideradas como reversões de condições localizadas em Macrocephala: (1) cirróforo reduzido a envoltório do cirro A e clava primária; (2) cabeça sem lobos distintos; e (3) coxa da perna IV distintamente encurtada.

A seguir estão relacionados os nós de cada subgrupo proposto para Digitopoda com suas respectivas sinapormorfias. Os ramos terminais, cujas sinapomorfias estão indicadas na Tabela 7, não foram incluídos abaixo. 


\section{Neostygarctus $^{+}$}

Batillipes $^{+}$: (1) ausência de placas cuticulares dorsais e ventrais (condição homoplástica também em Euclavarctinae + Styraconyxinae);

$(\text { Halechiniscinae }+ \text { Orzeliscinae })^{+}$: (1) dígitos com membrana cuticular protetora cobrindo totalmente as garras (condição homoplástica também em Euclavarctinae + Styraconyxinae);

Halechiniscinae + Orzeliscinae: (1) pedúnculos ausentes nos dígitos; e (2) dutos dos receptáculos seminais abrindo-se medianamente;

Dipodarctus $^{+}:$(1) projeções cuticulares laterais torácicas ausentes (reversão da condição localizada em Macrocephala e homoplástica também em Euclavarctinae + Styraconyxinae); (2) dígitos internos maiores que os dígitos externos (condição homoplástica também em Euclavarctinae + Styraconyxinae); (3) garras com ganchos de sustentação; e (4) comprimento das clavas primárias maior que os cirros A;

Florarctinae + Tanarctinae: (1) clavas secundárias desenvolvidas, de formas variadas (condição homoplástica também em Stygarctidae, Neostygarctus e Renaudarctus);

\section{Renaudarctus $^{+}$}

Euclavarctinae + Styraconyxinae: (1) projeções cuticulares laterais torácicas ausentes (reversão da condição localizada em Macrocephala e homoplástica também em Dipodarctus ${ }^{+}$); (2) dígitos com membrana cuticular protetora cobrindo totalmente as garras (condição homoplástica também em (Halechiniscinae + Orzeliscinae) ${ }^{+}$); (3) dígitos internos maiores que os dígitos externos (condição homoplástica também em Dipodarctus $^{+}$); (4) corpo delgado; e (5) ausência de placas cuticulares dorsais e ventrais (condição homoplástica também em Batillipes ${ }^{+}$). 


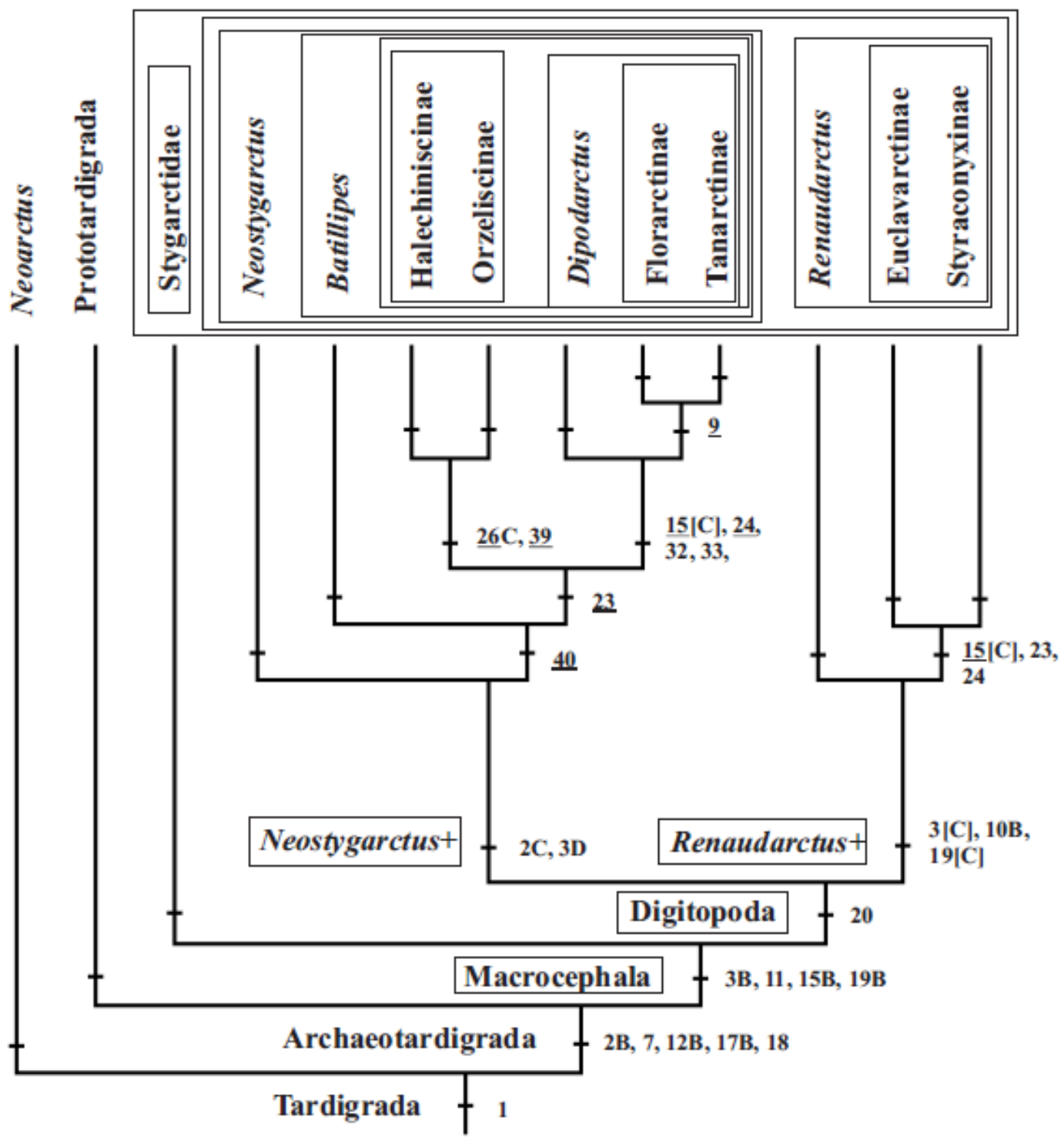

Figura 6 - Filogenia proposta para os 10 táxons terminais de Digitopoda. Total de 79 passos e índice de consistência 0,63. Somente nos nós principais foram indicadas sinapomorfias; caracteres grifados representam homoplasias; colchetes indicam reversões. 
Tabela 7 - Sistema filogenético seqüenciado para os subgrupos de Digitopoda. Caracteres diagnósticos, baseados exclusivamente em apomorfias, estão indicados em negrito e entre chaves; colchetes indicam reversões.

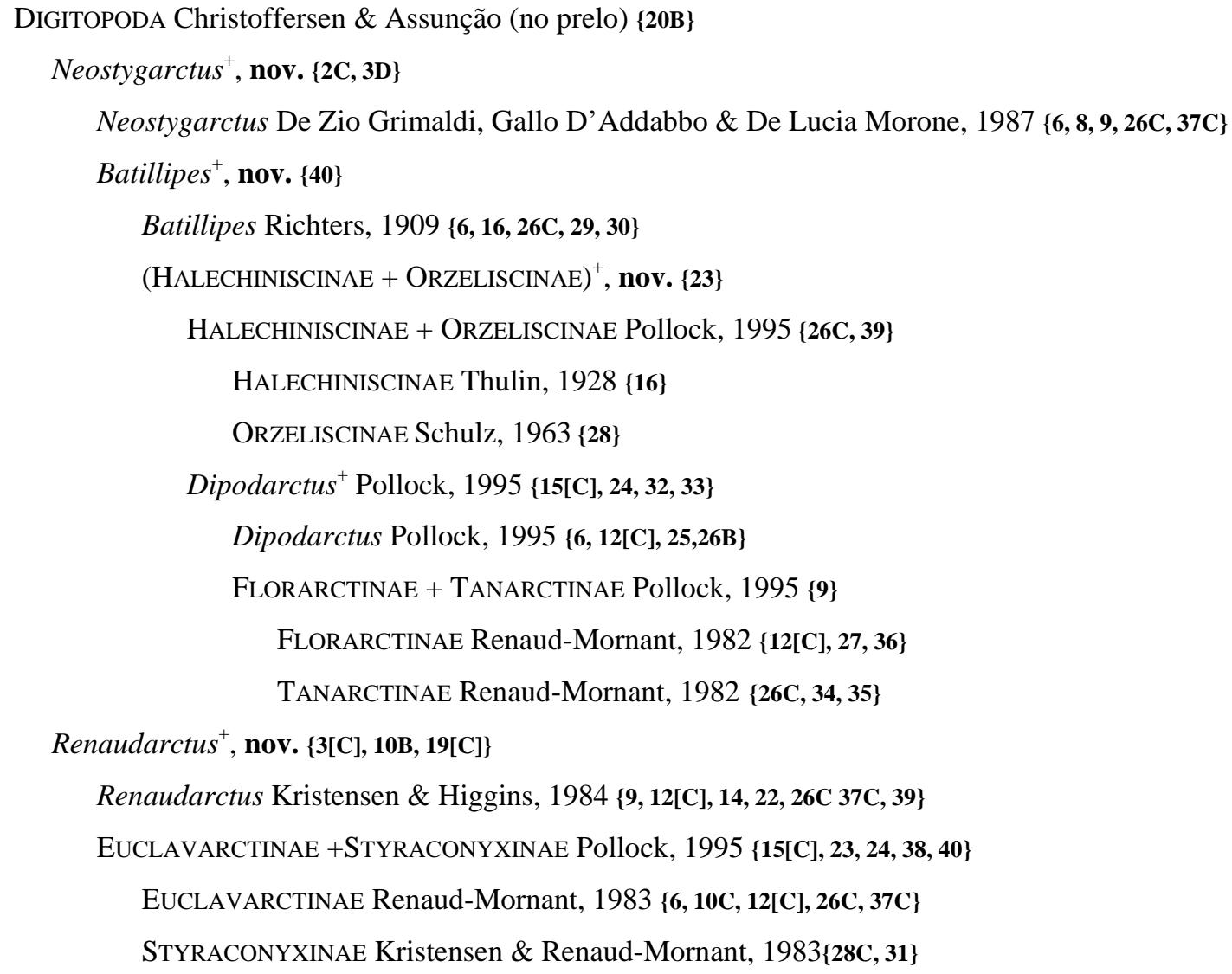

Podem ser considerados agrupamentos estáveis aqueles que se repetem tanto em filogenias anteriores (Fig. 4), como nos resultados aqui apresentados, i.e., na análise manual (Fig. 6, Tab. 7), e na análise numérica (Fig. 7, Tab. 8). São eles: Halechiniscidae + Orzeliscinae; Dipodarctus + Florarctinae + Tanarctinae; e Euclavarctinae + Styraconyxinae.

Seguem-se os resultados da análise numérica, que apresentou uma árvore de consenso (Fig. 7) com topologia radicalmente diferente e com menor número de passos que a árvore escolhida, apresentada na análise manual (Fig. 6). 
Tabela 8 - Matriz e lista de 40 caracteres (34 binários e 6 multiestado) e 10 táxons terminais de Digitopoda rodadas no programa Hennig 86. Algoritmo utilizado: mhennig*. Grupos externos em negrito.

\begin{tabular}{|c|c|}
\hline Neoarctus & 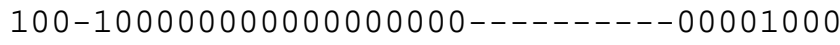 \\
\hline Prototardigrada & 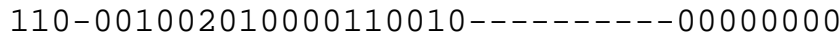 \\
\hline Stygarctidae & 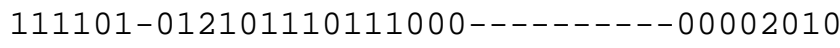 \\
\hline Neostygarctus & $122001-1101100101111000 \odot \odot 2-\odot \odot \odot \odot \odot \odot \odot \odot \odot 20 \odot \odot$ \\
\hline Batillipes & $122001-00011--11111100-002-011--0 \odot \odot \odot \odot \odot \odot 1$ \\
\hline Halechiniscinae & $12200010001 ?--11111100100 ? ? \odot \odot \odot \odot ? \odot \odot \odot \odot \odot \odot 11$ \\
\hline Orzeliscinae & $12200010001 ?--? 01111001002$ - $1000 \odot \odot \odot \odot \odot \odot \odot 11$ \\
\hline Dipodarctus & $1220 \odot 1-\odot \odot \odot 10--\odot \odot 11110 \odot 1111-\odot \odot \odot \odot 11 \odot \odot \odot \odot \odot \odot 1$ \\
\hline Florarctinae & $122000101010--001111001100100001100100 ? 1$ \\
\hline Tanarctinae & 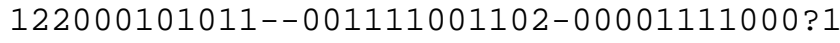 \\
\hline Renaudarctus & $110-\odot \odot 101110 \odot 1101101010 \odot \odot 2-\odot \odot \odot \odot \odot \odot \odot \odot \odot 2 \odot 1 \odot$ \\
\hline Euclavarctinae & $110-01-\odot \odot 210--0 \odot 11010 \odot 1102-\odot \odot \odot \odot \odot \odot \odot \odot \odot 2101$ \\
\hline Styraconyxinae & $110-0 \odot 10 \odot 111--\odot \odot 11010 \odot 110 \odot \odot 2 \odot \odot 1 ? \odot \odot \odot \odot \odot 101$ \\
\hline
\end{tabular}

1. Larva

[0] com três pares de pernas; [1] com quatro pares de pernas;

2. Cabeça (aditivo)

[०] alongada; [1] encurvada ventralmente; [2] fortemente encurvada para baixo;

3. Número de lobos cefálicos (não aditivo)

[0] nenhum; [1] seis; [2] lobos anteriores e medianos reduzidos;

4. Número de projeções agudas e voltadas para trás nos lobos cefálicos posteriores do adulto

[0] nenhuma; [1] uma projeção em cada lobo;

5. Cirróforo do cirro médio cefálico

[0] cônico; [1] arredondado;

6. Clavas terciárias

[0] presentes; [1] ausentes;

7. Posição das clavas terciárias na placa cuticular cefálica

[0] na região posterior; [1] na região cefálica anterior;

8. Parede das clavas secundárias

[0] fina; [1] espessa;

9. Forma das clavas secundárias

[○] não desenvolvidas, tipo domo; [1] desenvolvidas, de formas variadas;

10. Cirróforo robusto sustentando o cirro A e a clava primária (não aditivo)

[0] presente; [1] reduzido a envoltório em tôrno do cirro A e clava primária; [2] ausente;

11. Localização da placa escapular

[0] no tronco; [1] incorporada à cabeça;

12. Olhos

[0] ausentes; [1] presentes;

13. Poros nas placas ventrais

[0] ausentes; [1] presentes;

14. Placas intersegmentares

[0] ausentes; [1] presentes;

15. Projeções cuticulares laterais no tronco

[0] ausentes; [1] presentes;

16. Projeção cuticular pontiaguda única no segmento caudal

[0] ausente; [1] presente;

17. Articulações telescópicas nas pernas

[0] ausentes; [1] presentes;

18. Longo espinho terminal da papila sensorial da perna IV

[०] presente; [1] curto ou ausente; 
19. Tamanho da perna IV

[0] não alongada; [1] mais longa do que as pernas I-III;

20. Dígitos

[0] ausentes; [1] presentes;

21. Esporão basal nas garras das pernas I-IV

[0] ausente; [1] presente;

22. Filamentos nas garras

[0] ausentes; [1] presentes;

23. Membrana cuticular protetora cobrindo totalmente as garras dos dígitos

[०] ausente; [1] presente;

24. Comprimento dos dígitos internos nas pernas I a IV

[0] igual ao dos dígitos externos; [1] maior do que o dos externos;

25. Padrão de comprimento dos dígitos nas pernas I-III

[0] igual; [1] diferente da perna IV;

26. Pedúnculos nos dígitos (não aditivo)

[๑] presentes; [1] reduzidos a simples barras no tarso; [2] ausentes;

27. Forma dos pedúnculos

[0] retilíneos na extensão dos dígitos; [1] em forma de gancho na base dos dígitos;

28. Base dos dígitos (não aditivo)

[0] sem estruturas adesivas; [1] com estruturas adesivas alongadas;

[2] com estruturas adesivas cordiformes;

29. Extremidades dos dígitos

[0] sem estruturas adesivas; [1] com discos adesivos;

30. Número de dígitos

[0] quatro; [1] seis;

31. Ganchos acessórios nas garras dos dígitos internos

[0] ausentes; [1] presentes;

32. Ganchos de sustentação externos ("calcars") nas garras dos dígitos

[0] ausentes; [1] presentes;

33. Comprimento das clavas primárias

[0] menor ou igual que os cirros $A ;[1]$ maior que os cirros $A$;

34. Comprimento da papila da perna IV

[0] menor ou igual que o corpo; [1] maior que o corpo;

35. Longos pilares de sustentação da epicutícula

[0] ausentes; [1] presentes;

36. Expansões aliformes da cutícula

[0] ausentes; [1] presentes;

37. Suportes dos estiletes (não aditivo)

[๑] presentes; [1] modificados em baínha ao redor da faringe; [2] ausentes;

38. Forma do corpo

[0] cilíndrico; [1]. delgado;

39. Ductos dos receptáculos seminais

[0] abrindo-se lateralmente; [1] abrindo-se medianamente;

40. Placas cuticulares espessadas dorsais e ventrais

[0] presentes; [1] ausentes. 

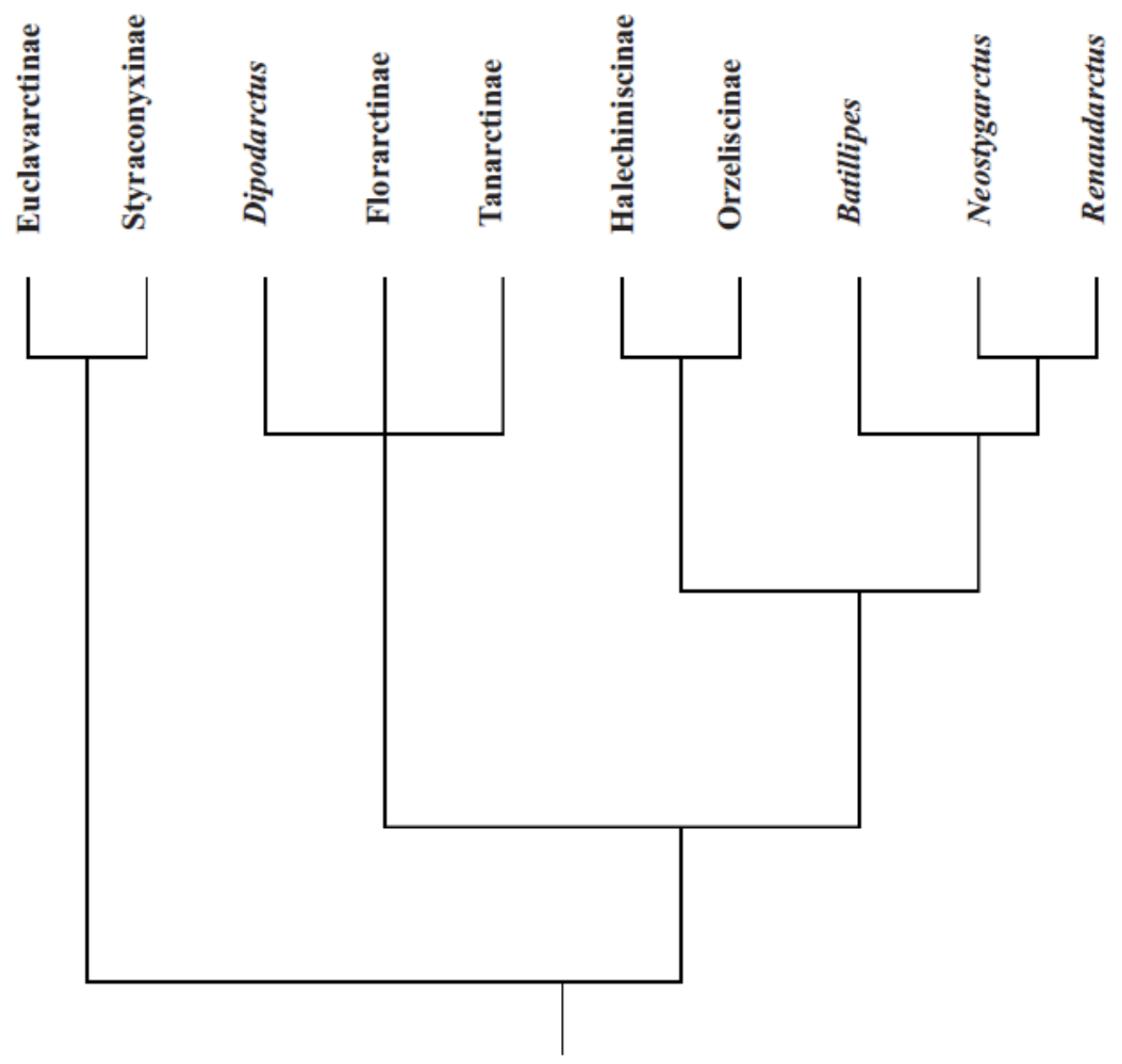

Figura 7 - Árvore de consenso - Tree Gardener 2.2 - Comprimento: 66 passos; índice de consistência: 0,68; índice de retenção: 0,63. 


\subsubsection{Relações filogenéticas propostas para Orzeliscinae}

Na análise de PolLOcK (1995), o monofiletismo de Orzeliscinae baseou-se em duas sinapomorfias: (1) dígitos alongados com complexas lâminas adesivas; e (2) ausência de garras. Com a inclusão de Paradoxipus em Orzeliscinae, apenas a primeira das sinapomorfias, ligeiramente modificada, se adequa ao monofiletismo deste táxon: (1) presença de estruturas adesivas em forma de espátulas na base dos dígitos.

O cladograma da Figura 8 representa o resultado da análise manual de dois caracteres multiestado para Orzeliscinae, cada um com dois estados apomórficos. O grupo é subdividido em Paradoxipus e Opydorscus + Orzeliscus, este último táxon baseado em duas sinapomorfias: (1) presença de estruturas adesivas em forma de espátulas em toda a extensão dos dígitos; e (2) ausência de garras somente nos dígitos das pernas II a IV. O último passo da série de transformação que envolve dígitos e garras na subfamília, a ausência de garras nos dígitos de todas as pernas, ocorre em Orzeliscus.

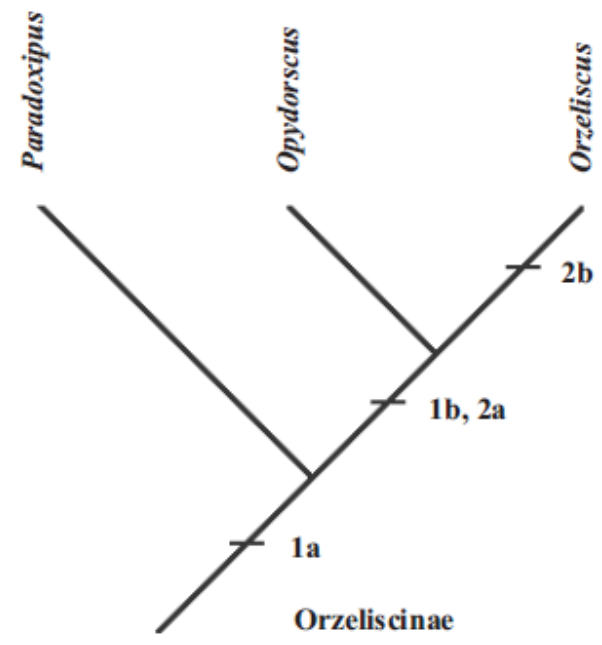

Figura 8 - Filogenia proposta para os 3 gêneros de Orzeliscinae. Total de 4 passos e índice de consistência 1. Descrição dos caracteres e seus estados: vide texto na seção de Discussão. 
Tabela 9 - Sistema filogenético seqüenciado para os subgrupos de Orzeliscinae. Caracteres diagnósticos para os nós, baseados exclusivamente em apomorfias, estão indicados em negrito e entre chaves.

\section{ORZELISCINAE Schulz, 1963 \{1a\}}

Paradoxipus Kristensen \& Higgins, 1989

P. orzeliscoides Kristensen \& Higgins, 1989 (espécie tipo)

Opydorscus + Orzeliscus, nov. $\{\mathbf{1 b}, \mathbf{2 a}\}$

Opydorscus Renaud-Mornant, 1990[1989]

O. fonsecae Renaud- Mornant, 1990[1989] (espécie tipo)

Orzeliscus Du Bois Reymond-Marcus, 1952 \{2b\}

O. belopus Du Bois Reymond-Marcus, 1952 (espécie tipo)

(sinônimo: O. septentrionalis Schulz, 1953) 


\section{DISCUSSÃo}

Uma mesma condição apomórfica aparente pode surgir mais de uma vez independentemente, gerando conflito entre os dados e problemas para a análise (AMORIM, 1997). São as chamadas "homoplasias”. A evolução homoplástica de muitos caracteres leva à consideração de caracteres apomórficos apenas como indício de monofiletismo entre os táxons, que pode ser testado posteriormente.

Os resultados obtidos neste trabalho são meramente hipóteses de relações de parentesco entre os subgrupos de Macrocephala, hipóteses estas não-estanques e com caracteres homoplásticos. Como toda análise filogenética, esta não poderia deixar de apresentar dificuldades com a delimitação correta, em alguns casos, de homologias primárias, e com a polarização de caracteres problemáticos.

Apesar disso, considera-se positivo o resultado da análise, que fornece contribuições importantes para a sistemática de tardígrados marinhos e, conseqüentemente, para a história evolutiva do grupo como um todo.

\subsection{Stygarctidae}

Bello \& De Zio Grimaldi (1998) desenvolveram uma análise cladística para Stygarctidae, mas falharam ao utilizar grupos não monofiléticos em sua proposta (e.g., Heterotardigrada, Arthrotardigrada e Echiniscoidea). Conseqüentemente, ocorreram erros de polarização de caracteres e novos grupos merofiléticos foram formados.

Ao propor o monofiletismo de Stygarctidae, BeLlo \& DE ZIO GRIMALdi (1998) indicaram uma única sinapomorfia, considerada no presente estudo como simplesiomórfica para Stygarctidae: posição posterior da clava primária em relação ao 
cirro A (ver caráter 27 da lista de caracteres de Stygarctidae). A polarização feita por esses autores baseou-se na condição encontrada em Halechiniscus e Renaudarctus, supostamente simplesiomórfica: posição anterior da clava primária em relação ao cirro A (Bello \& De Zio Grimaldi, 1998: 174, caráter 15). Entretanto, a condição encontrada nesses dois táxons tem um nível de generalidade restrito, condição esta que não é encontrada no nível mais abrangente dos Digitopoda, táxon monofilético no qual estão incluídos Halechiniscus e Renaudarctus.

A subdivisão de Stygarctidae em dois táxons também não é bem corroborada, pois separa Megastygarctides dos outros gêneros, reunidos em Stygarctinae (BELLO \& DE ZIO GRIMALDI, 1998). Os caracteres utilizados para redefinir este último táxon não são válidos: (1) região cefálica subdividida em cinco lobos, o lobo anterior originado por fusão de dois lobos; e (2) ausência de apêndices sensoriais nas pernas I-III. O primeiro caráter não se aplica a Parastygarctus, que conserva a condição plesiomórfica da região cefálica dividida em seis lobos (ver caráter 11 da lista de caracteres de Stygarctidae). O segundo caráter apresenta problemas quanto à sua real distribuição e ocorrência nos táxons envolvidos, como será visto mais adiante. Enfim, são inúmeras as lacunas deixadas por BELLO \& DE ZIo GRIMALDI (1998) em sua proposta.

Usando basicamente os mesmos grupos externos de BeLlo \& DE Zio GRIMALDI (1998), mas dispondo-os diferentemente, de acordo com o novo sistema dos Tardigrada (CHRISTOFFERSEN \& AsSUNÇÃO, no prelo), obteve-se um arranjo diferente para os gêneros de Stygarctidae (Fig. 5, Tab. 5). Desta maneira, demonstrou-se o risco envolvendo a escolha dos grupos externos quando hipóteses robustas da estrutura hierárquica ainda não são disponíveis no começo de uma análise cladística. 
Considera-se este resultado bastante conservativo, pois todos os gêneros foram mantidos. A diferença principal entre este resultado e aquele de BELLO \& DE ZIO GRIMALDI (1998) é o posicionamento de Megastygarctides, que aqui é tratado como grupo-irmão de Mesostygarctus + Pseudostygarctus. Os autores italianos consideraram-no como grupo basal dos Stygarctidae e criaram a sub-família Megastygarctidinae para abrigá-lo. Adicionalmente, também são propostas aqui as relações filogenéticas entre as espécies de todos os gêneros de Stygarctidae (Fig. 5, Tab. 5).

O fato de ter-se obtido na análise numérica (i.e., feita no programa Hennig 86) resultado idêntico ao manual (Fig. 5), pode ser considerado um indício de que os dados levantados e manipulados formaram uma boa base para o estudo aqui proposto.

Caracteres problemáticos, como presença/ausência de apêndices sensoriais nas pernas I-III, foram retirados da análise. Apêndices sensoriais podem não ter sido vistos em algumas espécies, pelos autores que as descreveram ou registraram (espécies de Parastygarctus; Stygarctus spinifer, S. granulatus, e espécies do grupo S. bradypus $^{+}$; espécies de Pseudostygarctus e Megastygarctides isounguis; ausente somente na perna I em Megastygarctides orbiculatus e nas pernas II e III em $M$. setoloso). Em Prototardigrada, os apêndices sensoriais das pernas I-III são perdidos independentemente nos Eutardigrada. Embora ausentes em Neostygarctus e em Renaudarctus, esses apêndices estão presentes em pelo menos algumas das pernas no restante dos sub-grupos de Neostygarctus ${ }^{+}$e de Renaudarctus $^{+}$, com exceção de Paratanarctus (ver caráter 18 da lista de caracteres de Digitopoda).

Outros caracteres duvidosos foram evitados na análise de Stygarctidae: a presença de placas cuticulares dorsais e ventrais e a ausência dos suportes dos estiletes são plesiomórficos neste nível e, portanto, não informativos; a variação morfológica do 
cirróforo e também o comprimento do cirro E foram considerados de difícil correlação nos táxons.

\subsection{Digitopoda}

Digitopoda é composto de duas linhagens principais não nomeadas: Neostygarctus ${ }^{+}$ e Renaudarctus ${ }^{+}$(Fig. 6, Tab.7). Na primeira estão incluídos alguns subgrupos de “Halechiniscidae” (i.e., Halechiniscinae, Orzeliscinae, Dipodarctinae, Florarctinae e Tanarctinae), além de Batillipedidae, que compartilham com Neostygarctus um forte encurvamento da região anterior cefálica, resultando em uma aparência truncada da cabeça em vista dorsal. Na segunda linhagem está incluído o restante dos táxons de “Halechiniscidae” (Euclavarctinae e Styraconyxinae) mais Renaudarctus, tendo como sinapomorfia principal a ausência de lobos cefálicos (i.e., divisão da região cefálica em lobos).

Archechiniscinae, utilizado como ramo terminal nas etapas iniciais da análise, foi removido da matriz de Táxons $\mathrm{X}$ Caracteres. Trata-se de um táxon monotípico redundante, posicionado por PoLLOCK (1995) como grupo-irmão de Styraconyxinae, este último desprovido de sinapomorfias no cladograma do referido autor (Fig. 4). Nesta análise, também não foram encontrados caracteres sinapomórficos para Styraconyxinae. Concluiu-se, então, que as principais sinapomorfias que unem os dois grupos (caracteres 29C e 32B da lista de caracteres de Digitopoda) justificam a criação de um único grupo monofilético. Optou-se por manter o nome da subfamília mais numerosa (Styraconyxinae) e incorporar Archechiniscus a esse grupo. As relações entre Archechiniscus e os demais gêneros de Styraconyxinae não puderam ser estabelecidas neste estudo. 
O arranjo aqui proposto (Fig. 6, Tab.7) muda radicalmente as relações previamente estabelecidas para os táxons envolvidos. Halechiniscidae foi desmembrado e o subgrupo mais numeroso proposto por PoLlOcK (1995) (Fig. 4) também foi desfeito. Os táxons mais estáveis foram conservados neste estudo (Halechiniscidae + Orzeliscinae; Dipodarctus + Florarctinae + Tanarctinae; e Euclavarctinae + Styraconyxinae), contudo passaram a ocupar novas posições dentro do sistema hierárquico dos Digitopoda. A inclusão de Neostygarctus e Renaudarctus no grupo contribuiu para esse rearranjo, mas, por outro lado, criou uma incongruência entre os caracteres envolvidos nessa reconstituição.

A proposição do evento cladogenético que separa Digitopoda em duas linhagens, com base principalmente na evolução dos caracteres que envolvem a região cefálica (caracteres 2, 3 e 10B), implica na proposição de ocorrências homoplásticas para caracteres até então considerados de origem única (caracteres 23, 24 e 40). Os dois primeiros envolvem os dígitos, estruturas relativamente bem estudadas nos táxons halequinisciformes, mas que ainda necessitam de aprofundamento quanto à morfologia nos táxons digitiformes basais (Neostygarctus, Renaudarctus e Batillipes). O conhecimento de novas espécies com estruturas complexas nos dígitos, como $O$. fonsecae e $P$. orzeliscoides (ver seções 1.2.1, 4.4.1 e 5.2.1), contribui para a compreensão da evolução dos táxons que os possuem. O caráter 40 diz respeito à perda de placas, que também ocorre em subgrupos de Prototardigrada, e portanto não representa um argumento definitivo contra a hipótese de origem única das condições encontradas nos caracteres 2 e 3, e do caráter 10B. Somente com a realização de novos estudos será possível acrescentar mais caracteres à análise e assim propor o estabelecimento completo e mais informativo das relações filogenéticas dos táxons de Digitopoda. 
A disparidade entre as topologias obtidas na análise manual (Fig. 6) e na análise numérica (Fig. 7), revela a existência de problemas com os dados. O número de caracteres sinapomórficos levantados é relativamente pequeno com relação ao número de táxons terminais, e é elevado o número de caracteres homoplásticos, responsáveis pelas incongruências que confundem e distorcem o resultado final. Adicionalmente, a informação é perdida quando, na codificação dos estados em que são inferidas reversões, é utilizado 0 indistintamente para os táxons que apresentam a condição plesiomórfica do caráter.

No caso de Digitopoda, além desses problemas, caracteres com estados simplificados, como o caráter 9 (clavas secundárias modificadas, de formas variadas) (Tab. 8), são discutíveis, pois contribuem com informação limitada, empobrecendo a matriz. Esse é um dos caracteres que unem Neostygarctus e Renaudarctus, no resultado numérico (Fig. 7). No entanto, as clavas secundárias nesses táxons são completamente diferentes. Condições plesiomórficas também estão compartilhas por esse suposto grupo monofilético (e.g., ausência de membranas cuticulares protetoras nas garras e presença de placas cuticulares, caracteres 23 e 40, respectivamente), numa inversão de polaridade desses caracteres.

\subsubsection{Orzeliscinae}

O gênero Paradoxipus, erroneamente incluído em Halechiniscinae, como visto anteriormente, foi incorporado aos Orzeliscinae. Na reconstrução das modificações ocorridas na história dos dígitos com “espátulas adesivas”, as condições observadas em Paradoxipus, Opydorscus e Orzeliscus representam apenas algumas das diversas mudanças que os dígitos sofreram ao longo da evolução dos orzeliscíneos. A condição 
plesiomórfica, isto é, ausência de tais estruturas nos dígitos, ocorre em todos os outros táxons de Tardigrada. A partir desta condição ocorreu uma sucessão de modificações, das quais duas transições podem ser hipotetizadas, observando-se as condições encontradas nos três táxons citados (Fig. 6).

A primeira transição produz o aparecimento de 'estruturas adesivas em forma de espátulas’ na base dos dígitos (estado 1a), que ocorre no ancestral hipotético desses grupos e é conservado em Paradoxipus. A segunda transição leva à presença dessas estruturas em toda a extensão dos dígitos (estado 1b), sendo compartilhado por Opydorscus e Orzeliscus.

Um outro caráter, presença/ausência de garras nos dígitos, diretamente relacionado às modificações descritas, reforça a hipótese de filogenia entre esses gêneros. A condição observada em Paradoxipus - presença de garras nos dígitos de todas as pernas - é plesiomórfica (ocorre em todos os outros halechiniscídeos). O primeiro passo (estado 2a: ausência de garras somente nos dígitos das pernas II-IV) ocorre no ancestral exclusivo de Opydorscus e Orzeliscus. Esta condição foi conservada somente nas fêmeas de Opydorscus. O segundo passo (estado 2b: ausência de garras nos dígitos de todas as pernas) é autapomórfico para Orzeliscus.

As mudanças propostas a partir de hipóteses baseadas nos princípios e métodos da Sistemática Filogenética contribuem para o conhecimento em Tardigrada. As relações de parentesco entre os subgrupos de Macrocephala apresentam-se bem resolvidas. Stygarctidae, a subunidade menos numerosa, tem sua filogenia resolvida até o nível de suas 17 espécies. Digitopoda, táxon que reúne o maior número de espécies marinhas (114 espécies), foi resolvido no nível dos táxons superiores que o constituem. Por fim, Orzeliscinae foi rearranjado, e as três espécies com espátulas adesivas nos dígitos tiveram suas interrelações totalmente resolvidas. 


\section{CONCLUSÕES}

1 - Stygarctidae é um táxon monofilético dividido em duas linhagens: a primeira inclui Parastygarctus e Stygarctus, ambos monofiléticos; a segunda inclui Megastygarctides, Mesostygarctus e Pseudostygarctus, também monofiléticos e seqüenciados filogeneticamente na ordem apresentada;

2 - Neostygarctidae, Renaudarctidae, Neoarctidae e Megastygarctidinae são táxons monotípicos, ilógicos, e foram eliminados do sistema dos Tardigrada;

3 - Digitopoda é subdividido em dois agrupamentos monofiléticos: Neostygarctus ${ }^{+}$e Renaudarctus ${ }^{+}$

3 - Halechiniscidae não forma um táxon monofilético;

4 - Halechiniscinae constitui um táxon monofilético mais restrito que inclui apenas Halechiniscus e Chrysoarctus;

5 - Orzeliscinae constitui um táxon monofilético mais abrangente dentro do sistema dos Digitopoda, estando os seus sub-grupos, Paradoxipus, Opydorscus e Orzeliscus, seqüenciados filogeneticamente;

6 - Styraconyxinae tem nova abrangência, pois inclui também Archechiniscus;

7 - Archechiniscinae não é válido. 


\section{Resumo}

Foi realizado um estudo das relações filogenéticas de Stygarctidae e Digitopoda (Tardigrada, Archaeotardigrada, Macrocephala) seguindo-se os princípios e métodos henniguianos. Foram selecionados na literatura os caracteres morfológicos utilizados para os dois grupos: 61 caracteres (43 binários e 18 multiestado) para 17 táxons terminais, de Stygarctidae, ao nível de espécie, e 40 caracteres (31 binários e 9 multiestado) para 10 táxons superiores de Digitopoda. As análises manuais produziram cladogramas totalmente resolvidos com 101 passos evolutivos e índice de consistência 0,86 para Stygarctidae, e 79 passos evolutivos e índice de consistência 0,63 para Digitopoda. Também foram feitas análises numéricas, com o auxílio do programa Hennig 86, comparando-se os resultados destas com as análises manuais. O algoritmo utilizado foi o mhennig*. O consenso de duas árvores de Stygarctidae apresentou topologia idêntica à do cladograma supracitado, com 98 passos evolutivos, índice de consistência 0,77 e índice de retenção 0,82. No caso de Digitopoda, o consenso de duas árvores apresentou uma topologia radicalmente diferente do resultado manual, com 66 passos evolutivos, índice de consistência 0,68 e índice de retenção 0,63. Também foram analisados dois caracteres multiestado, cada um com duas condições apomórficas, para três táxons terminais (nível de espécie) de Orzeliscinae. Neste caso, o cladograma obtido apresentou quatro passos evolutivos e índice de consistência 1. Stygarctidae foi mantido como táxon monofilético, apresentando a seguinte topologia entre os seus gêneros: ((Parastygarctus + Stygarctus $)+(($ Mesostygarctus + Pseudostygarctus $)+$ Megastygarctides $))$. Digitopoda foi subdividido em dois táxons monofiléticos, apresentando a seguinte

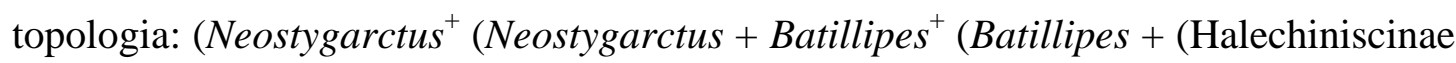
+ Orzeliscinae $^{+}\left((\right.$Halechiniscinae + Orzeliscinae $)+$Dipodarctus $^{+}\left(\right.$Dipodarctus $^{+}$ $($ Floractinae + Tanarctinae $)))))+$ Renaudarctus $^{+}($Renaudarctus $+($Euclavarctinae + Styraconyxinae))). Halechiniscidae não é monofilético e Halechiniscinae é um táxon mais restrito, que inclui apenas Halechiniscus e Chrysoarctus. Orzeliscinae é redefinido de forma a incluir Paradoxipus, grupo-irmão de Opydorscus + Orzeliscus. Styraconyxinae inclui também Archechiniscus. Archechiniscinae não é válido. Neostygarctidae, Renaudarctidae, Neoarctidae e Megastygarctidinae foram eliminados do sistema de Tardigrada. 


\section{Abstract}

Relationships among the subgroups of Stygarctidae and Digitopoda (Tardigrada, Archaeotardigrada, Macrocephala) were invetigated according to hennigian principles and methods. Morphological characters were selected from the literature for these two groups: 61 characters (43 binary and 18 multistate) for 17 species of Stygarctidae and 40 characters (31 binary and 9 multistate) for 10 major groups of Digitopoda. Manual analysis produced fully resolved cladograms with 101 evolutionary steps and consistency index $=0,86$ for Stygarctidae, and 79 evolutionary steps and consistency index $=0,63$ for Digitopoda. Numerical analysis were done using the software Hennig 86, for comparison with manual analysis. The algoritm mhennig* was used. The consensus tree of two Stygarctidae trees showed identical topology with the manual cladogram, with 98 evolutionary steps, consistency index $=0,77$ and retention index $=$ 0,82. The consensus tree of two Digitopoda trees showed a complete diferent topology from the manual cladogram, with 66 evolutionary steps, consistency index $=$ 0,68 and retention index $=0,63$. There were also analysed two multistate characters, each one with two apomorphic conditions, for three Orzeliscinae species. In this case, another fully resolved cladogram with four evolutionary steps and consistency index = 1 was obtained. Stygarctidae was maintained as a monophyletic taxon, showing the following system for its genera: ((Parastygarctus + Stygarctus) $+(($ Mesostygarctus + Pseudostygarctus) + Megastygarctides)). Digitopoda, branched into two monophyleitc taxa, showed the following system: (Neostygarctus ${ }^{+}$(Neostygarctus +

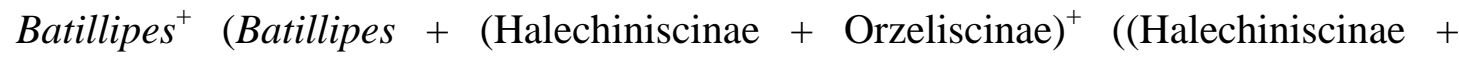
Orzeliscinae $)+$ Dipodarctus $^{+}\left(\right.$Dipodarctus $^{+}($Floractinae + Tanarctinae $\left.\left.\left.\left.)\right)\right)\right)\right)+$ Renaudarctus $^{+}$(Renaudarctus + (Euclavarctinae + Styraconyxinae))). Halechiniscidae is not a monophyletic taxon and Halechiniscinae is a more inclusive taxon comprising only Halechiniscus and Chrysoarctus. Orzeliscinae includes Paradoxipus, the sistergroup of Opydorscus + Orzeliscus. Styraconyxinae is monophyletic with the inclusion of Archechiniscus. Archechiniscinae is not valid. Neostygarctidae, Renaudarctidae, Neoarctidae and Megastygarctidinae are not supported in the system of the Tardigrada. 


\section{REFERÊNCIAS BIBLIOGRÁFICAS}

Aguinaldo, A.M.A.; TurbeVILle, J.M.; Linford, L.S.; RiverA, M.C.; GAREY, J.R.; RAFF, R.A. \& LAKE, J.A. 1997. Evidence for a clade of nematodes, arthropods and other moulting animals. Nature, 387:489-493.

Almeida, W.O. \& Christoffersen, M.L. 2000. Análise cladística dos grupos basais de Metameria: uma nova proposta para o posicionamento dos Arthropoda e grupos afins entre os poliquetos errantes. Série Teses, Dissertações e Monografias, n. 1. Holos, Ribeirão Preto. 76p.

AMORIM, D.S. 1982. Classificação por sequenciação: Uma proposta para a denominação dos ramos retardados. Rev. Bras. Zool., 1: 1- 9.

AMORIM, D.S. 1997. Elementos básicos de sistemática filogenética. 2ª edição. Holos, Ribeirão Preto. 276p.

AssunçÃo, C.M.L. \& Christoffersen, M.L. 1994. Phylogenetic analysis of the Tardigrada. Abstr.VI Int. Symp. Tardigrada, Cambridge, U.K., August 22-26, 1994.

Bello, G.\& De Zio Grimaldi, S. 1998. Phylogeny of the genera of Stygarctidae and related families (Tardigrada: Heterotardigrada). Zool. Anz., 237: 171-183.

Bertolani, R. \& Biserov, V.I. 1996. Leg and claw adaptations in soil tardigrades, with erection of two new genera of Eutardigrada, Macrobiotidae: Pseudohexapodibius and Xerobiotus. Inv. Biol., 115 (4): 299-304.

Bussau, C. 1992. New deep-sea Tardigrada (Arthrotardigrada, Halechiniscidae) from a manganese nodule area of the eastern South Pacific. Zool. Scr., 21: 79-91.

CHANG, C.Y. \& RHO, H.S. 1996. Isohypsibius granditintinus, a new psammobenthic tardigrade from an estuary of South Korea. Kor. J. Syst. Zool., 12: 245-252. 
ChAng, C.Y. \& RHO, H.S. 1998. Three new tardigrade species associated with barnacles from the Thai Coast of Andaman Sea. Korean J. Biol. Sci., 2: 323-331.

Christoffersen, M.L. 1989. Phylogeny and classification of Pandaloidea (Crustacea, Caridea). Cladistics, 5 (3): 259-274.

Christoffersen, M.L., Amorim, D.S. \& Marques, A.C. 1997. Monophyly of the Ecdysozoa: support from morphology. Program and Abstracts. $16^{\text {th }}$ Meeting of the Willi Hennig Society, Washington.

Christoffersen, M.L. \& AssunÇÃo, C.M.L. Tardigrades and emergent clades: a new framework. J. Comp. Biol., 4 (1/2). No Prelo.

De Lucia Morone, M.R.; De Zio Grimaldi, S. \& Gallo D'Addabbo, M. 1984. Description of Parastygarctus biungulatus n. sp. and hypothesis of phylogeny in the Stygarctidae family (Heterotardigrada: Arthrotardigrada). Oebalia, 10: 85-94.

De Zio Grimaldi, S., Gallo D'Addabbo, M. \& De Lucia Morone, M.R. 1982. Neostygarctus acanthophorus, n.gen., n.sp., nuovo tardigrado marino del Mediterraneo. Cah. Biol. Mar., 23: 319-323.

De Zio Grimaldi, S., Gallo D'Addabbo, M. \& De Lucia Morone, M.R. 1987. Adaptive radiation and phylogenesis in marine Tardigrada and the establishment of Neostygarctidae, a new family of Heterotardigrada. Boll. Zool., 54: 27-33.

De Zio Grimaldi, S.; Gallo D'Addabbo, M. \& De Lucia Morone, M.R. 1992. Neoarctus primigenius n.g., n.sp., a new Stygarctidae of the Tyrrhenian Sea (Tardigrada, Arthrotardigrada). Boll. Zool., 59 (3): 309-313.

De Zio Grimaldi, S., Gallo D'Addabbo, M. \& De Lucia Morone, M.R. 1998. A new Stygarctidae from South Tyrrhenian Sea (Tardigrada, Heterotardigrada). Cah. Biol. Mar., 39: 85-91. 
De Zio Grimaldi, S.; Gallo D'Addabbo, M.; De Lucia Morone, M.R \& D'AdDABbo, L. 1988. Marine Arthrotardigrada and Echiniscoidea (Tardigrada, Heterotardigrada) from the Indian Ocean. Boll. Zool., 54 (4): 347-357.

Du Bois-Reymond Marcus, E. 1952. On South American Malacopoda. Bol. Zool., Univ. S. Paulo, 17: 186-209.

FARRIS, J.S. 1989. Hennig 86: a PC-DOS program for Phylogenetic Analysis. Cladistics, 5: 163-166.

Gallo D’Addabbo, M., De Zio Grimaldi, S., \& D’AddabBo, R. 2000. Pseudostygarctus apuliae (Tardigrada, Heterotardigrada): a new species from the lower Adriatic Sea. Ital. J. Zool., 67: 125-128.

Gallo D’Addabbo, M., Pietanza, R., D’Addabbo, R., De Lucia Morone, M.R. \& DE Zio Grimaldi, S. 1999. A redescription of Actinarctus doryphorus (Tardigrada, Heterotardigrada). Cah. Biol. Mar., 40: 21-27.

Hallas, T.E. \& Kristensen, R.M. 1982. Two new species of the tidal genus Echiniscoides from Rhode Island, U.S.A. (Echiniscoididae, Heterotardigrada), p. 179-192. In: NELSON, D. (ed.), Proceedings of the Third International Symposium on the Tardigrada, Aug. 3, 1980, Johnston City, Tennessee. East Tennessee University Press, Johnston City, Tennessee.

Hennig, W. 1965. Phylogenetic systematics. Ann. Rev. Entomol., 10: 97-116.

HenNiG, W. 1966. Phylogenetic systematics. Illinois Univ. Press, Urbana, 263p.

HiRUTA, S. 1985. A new species of marine interstitial Tardigrada of the genus Stygarctus Schulz from Hokkaido, Japan. Spec. Publ. Mukaishima Mar. Biol. Stn., 1985: 127-129.

JØRGENSEN, A. 2000. Cladistic analysis of the Echiniscidae Thulin, 1928 (Tardigrada: Heterotardigrada: Echiniscoidea). Streenstrupia, 25: 11-23 
Kinchin, I.M. 1994. The biology of tardigrades. Portland Press, London, p. i-xi, 1186.

KINCHIN, I.M. 1995. Evolutionary trends in the tardigrades. Queck. J. Micr., 37: 493498.

KRISTENSEN, R.M. 1987. Generic revision of the Echiniscidae (Heterotardigrada), with a discussion of the origin of the family, p. 261-335. In: BERTOLANI, R. (ed.), Biology of tardigrades. Selected Symposia and Monographs, n. 1. Collana U.Z.I. (Unione Zool. Ital.), Mucchi, Modena.

Kristensen, R.M. \& Higgins, R.P. 1984a. A new family of Arthrotardigrada (Tardigrada: Heterotardigrada) from the Atlantic coast of Florida. Trans. Amer. Micr. Soc. 103, (3): 295-311.

KRISTENSEN, R.M. \& Higgins, R.P. 1984b. Revision of Styraconyx (Tardigrada: Halechiniscidae), with descriptions of two new species from Disko Bay, West Greenland. Smiths. Contr. Zool., n. 391:1-40.

KRISTENSEN, R.M. \& Higgins, R.P. 1989. Marine Tardigrada from the southeastern USA coastal waters: I. Paradoxipus orzeliscoides, new genus new species (Arthrotardigrada: Halechiniscidae). Trans. Am. Microsc. Soc., 108 (3): 262-282.

KRISTENSEN, R.M. \& RENAUd-MoRnANT, J. 1983. Existence d'Arthrotardigrades semi-benthiques de genres nouveaux de la sous-famille des Styraconyxinae subfam. nov. Cah. Biol. Mar., 24 (3): 337-354.

MAdDison, W.P., Donoghe, M.J. \& MAdDison, D.R. 1984. Outgroup analysis and parsimony. Syst. Zool., 33: 83-103.

MARCuS, E. 1927. Zur Anatomie und Ökologie mariner Tardigraden. Zool. Jahrb., Abt. Syst. Ökol. Geog. Tiere, 53: 487-558. 
MArcus, E. 1929. Tardigrada, p. 1-608, 1 pl. In: BronN, H.G. (ed.), Klassen und Ordnungen des Tier-Reichs, Band 5 (Abt. 4, Buch 3). Akademische Verlagssgesellschaft, Leipzig.

Marcus, E. 1936. Tardigrada, p. i-xvii, 1-340. In: Schulze, F.E.; W. KÜKENTHAL \& K. HeIDER (eds.), Das Tierreich, Lief 66. Walter de Gruyter, Berlin.

MAY, R.M. 1953. L'évolution des tardigrades de la vie aquatique à la vie terrestre. Bull. Franç. Pisc., n. 168: 93-100.

McKirdy, D., Schmidt, P.\& McGinty-BAyly, M. 1976. Interstitielle Fauna von Galapagos. XVI. Tardigrada. Mikrof. Meeresb., 58: 409-499.

Miller, W.R. \& Kristensen, M.R. 1999. Tardigrades of the Australian Antarctic: a new species of the marine genus Echiniscoides from Macquarie Island, Subantarctica. Zool. Anz. 238: 289-294.

Morgan, C.I. \& O'Reilly, M. 1988. Additions to the Scottish tardigrade fauna, including a description of Megastygarctides setoloso new species, with a revised key for the identification of Scottish marine species. Glasg. Nat., 21: 445-454.

MourA, G. \& Christoffersen, M.L. 1996. The system of the mandibulate arthropods: Tracheata and Remipedia as sister groups, 'Crustacea' nonmonophyletic. J. Comp. Biol., 1: 95-113.

MÜLLeR, K.J.; WALOSSEK, D. \& ZaKhARov, A. 1995. Örsten-B4 type phosphatized soft-integument preservation and a new record from the Middle Cambrian Kuonamka Formation of Siberia. N. Jb. Geol. Palaeont., Abh., 191 (1): 101-118.

NiXON, K.C. \& CARPENTER, J.M. 1993. On outgroups. Cladistics, 9 (4): 413-426.

NoDA, H. 1985. Description of a new subspecies of Angursa bicuspis Pollock (Heterotardigrada, Halechiniscidae) from Tanabe Bay, Japan. Publ. Seto Mar. Biol. Lab., 30: 269-276. 
DE PinNA, M. 1991. Concepts and tests of homology in the cladistic paradigm. Cladistics, 7: 367-394.

PollOCK, L.W. 1970. Batillipes dicrocercus n. sp., Stygarctus granulatus n.sp. and other Tardigrada from Woods Hole, Massachusetts, USA. Trans. Amer. Micr. Soc., 89: 38- 52.

Pollock, L.W. 1982. A closer look at some marine Heterotardigrada. I. The morphology and taxonomy of Orzeliscus. In: Nelson, D. (ed.) Proceedings of the Third International Symposium on Tardigrada, 1980. Johnson City, Tennessee: East Tennessee State University Press, 193-202.

PollOCK, L.W. 1995. New marine tardigrades from Hawaiian beach sand and phylogeny of the family Halechiniscidae. Inv. Biol., 114 (3): 220-235.

RAHM, P.G. 1937. A new ordo of tardigrades from the hot springs of Japan. Annot. Zool. Japon., 16: 345-352.

RAMAZzotTI, G. \& MAUCCI W. 1982. A history of tardigrade taxonomy, p. 13-30. In: NELson, D. (ed.), Proceedings of the Third International Symposium on the Tardigrada, Aug. 3, 1980, Johnston City, Tennessee. East Tennessee State University Press, Johnston City, Tennessee.

Ramazzotti, G. \& MAucci, W. 1983. Il phylum Tardigrada (3d. ed.). Mem. Ist. Ital. Idrob. Dott. M. Marchi, 41: 1-1012.

RAMOS, T.C. 1996. Tree Gardener version 2.2. P.C. program for windows.

RENAUd-DeBYSER, J. 1965a. Parastygarctus higginsi n.g., n.sp. Tardigrade marin interstitiel de Madagascar. C. R. Hebd. Sc. Acad. Sci. Paris., 260: 955-957.

RENAUd-DEBysER, J. 1965b. Étude sur un stygarctidé (Tardigrada) nouveau de Madagascar. Bull. Soc. Zool. France, 90: 31-38. 
RENAud-MoRnANT, J. 1967. Parastygarctus higginsi Renaud-Debyser, 1965, sur la côte Orientale de Malaise. Description de la femelle (Tardigrada). Bull. Mus. Natl. Hist. Nat., 2e sér., 39: 205-208.

RENAUd-MoRnANT, J. (1970): Parastygarctus sterreri n.sp., tardigrade marin nouveau de l'Adriatique. Cah. Biol. Mar., 9: 355-360.

Renaud-MoRnANT, J. 1979. Tardigrades marins de Madagascar. 2. Stygarctidae et Oreellidae. 3. Considérations écologiques génerales. Bull. Mus. Natn. Hist. Nat. Paris (Zool. Biol. Ecol. Anim.), 2: 339-351.

RENAUD-MoRnANT, J. (1981a): Stygarctus gourbaultae n.sp. un nouveau Tardigrade marin (Arthrotardigrada) de la Guadeloupe. Bull. Mus. Natl. Hist. Nat. Paris (Zool. Biol. Ecol. Anim.), 3: 175-180.

REnAud-MornAnT, J. (1981b): Tardigrades marins (Arthrotardigrada) du Pacifique Sud. Bull. Mus. Natl. Hist. Nat., Paris, 4e sér., sect. A, 3: 799-813.

RENAud-MoRnant, J. 1984. Halechiniscidae (Heterotardigrada) de la campagne Benthedi, Canal du Mozambique. Bull. Mus. Natl. Hist. Nat., Paris (Zool. Biol. Ecol. Anim.), 6 (1): 67-88.

RENAUD-MORNANT, J. 1987. Halechiniscidae nouveaux de sables coralliens tropicaux (Tardigrada, Arthrotardigrada). Bull. Mus. Natl. Hist. Nat. Paris (Zool. Biol. Ecol. Anim.), 9 (2): 353-374.

Renaud-Mornant, J. 1988. Tardigrada, p. 357-364. In: Higgins, R.P. \& THIEL, H. (eds.), Introduction to the study of meiofauna, Smithsonian Institution Press, Washington, D.C.

RENAUD-MoRnANT, J. 1989. Opydorscus, un nouveau genre d'Orzeliscinae et sa signification phylogenique (Tardigrada, Arthrotardigrada). Bull. Mus. Natl. Hist. Nat. Paris, 4esér., 11: 763-771. 
Renaud-Mornant, J. \& Anselme-Moizan, M.N. 1970. Stades larvaires du tardigrade marin Stygarctus bradypus Schulz et position systématique des Stygarctidae. Bull. Mus. Natl. Hist. Nat., Paris, 2e sér., 41: 883-893.

Schulz, E. 1953. Orzeliscus septentrionalis n. sp. ein neuer mariner Tardigrad an der deutschen Nordseekuste. Kieler Meeresforschungen, 9: 288-292.

ViLlorA-Moreno, S.A. 1996. A new genus and species of the deep-sea family Coronarctidae (Tardigrada) from a submarine cave with a deep-sea like condition. Sarsia, 81 (4): 275-283.

WAtrous, L.E. \& WhEeler, Q.D. 1981. The out-group comparison method of character analysis. Syst. Zool., 30: 1-11.

WiLEY, E.O. 1981. Phylogenetics. The theory and practice of phylogenetic systematics. New York: John Wiley \& Sons, 439p. 